\title{
Sociedad Española del Dolor (SED). Recomendaciones asistenciales para unidades de dolor ante la normalización progresiva de la actividad durante la pandemia por COVID-19
}

\section{Spanish Pain Society [SPS]. Healthcare recommendations for pain units in the face of progressive normalization of activity during the COVID-19 pandemic}

V. Mayoral Rojals, C. Pérez Hernández², J. Pérez Cajaraville³, A. Canós Verdecho y Grupo de apoyo*

${ }^{1}$ Unidad de Dolor. Hospital Universitari de Bellvitge. L'Hospitalet de Llobregat, Barcelona, España. ${ }^{2}$ Unidad de Dolor. Hospital Universitario de la Princesa. Madrid, España. ${ }^{3}$ Unidad de Dolor. HM Hospitales. Madrid, España. ${ }^{4}$ Unidad de Dolor. Hospital Universitari i Politècnic La Fe. Valencia, España

*Sergi Boada Pie (Unidad de Dolor. Hospital Universitari Joan XXIII. Tarragona), Patricia Alfaro de la Torre (Unidad de Dolor. Hospital Universitari Joan XXIII. Tarragona), José Manuel Trinidad-Arroyo (Unidad del Dolor. Hospital Puerta del Mar. Cádiz], Jaime Boceta Osuna [Unidad de Hospitalización Domiciliaria y Cuidados Paliativos. Hospital Universitario Virgen Macarena. Sevilla], Carlos Luis Nebreda [Unidad de Dolor. Instituto Aliaga. Centro Médico Teknon-Quirón Salud. Barcelona), Luz Cánovas Martínez (Unidad de Dolor. Complexo Hospitalario Universitario de Ourense), Juan Francisco Mulero Cervantes (Unidad de Dolor. Hospital General Universitario Santa Lucía. Cartagena), César Margarit Ferri (Unidad de Dolor. Hospital General de Alicante), Enrique Ortega Ladrón de Cegama (Unidad Dolor Valladolid - Alianza HURH\&HCUVA. Valladolid), Alfonso Carregal Rañó (Unidad de Dolor. Complexo Hospitalario Universitario de Vigo), Miguel Ángel Caramés Álvarez (Unidad de Dolor. Hospital Universitario de Gran Canaria Doctor Negrín. Las Palmas de Gran Canaria), Javier Vidal Fuentes (Reumatología. Hospital General y Universitario de Guadalajara), Diego Contreras de la Fuente (Presidente pasado de la SED) y Juan Antonio Micó Segura [Cátedra de Farmacología. Universidad de Cádiz]

\section{ABSTRACT}

Introduction: SARS-CoV-2 infection is a new viral infection that has emerged in the form of a pandemic, with a respiratory and multisystemic clinical spectrum, which causes high morbidity and mortality. Its rapid expansion is dependent on the absence of previous exposure and immunity, the absence of a vaccine and
RESUMEN

Introducción: La infección por SARS-CoV-2 es una nueva infección viral que ha emergido en forma de pandemia, con un espectro clínico respiratorio y multisistémico, que ocasiona una elevada morbimortalidad. Su rápida expansión es dependiente de la ausencia de exposición e inmunidad previas, la ausencia de vacuna
Mayoral Rojals V, Pérez Hernández C, Pérez Cajaraville J, Canós Verdecho A y Grupo de apoyo*. Sociedad Española del Dolor (SED). Recomendaciones asistenciales para unidades de dolor ante la normalización progresiva de la actividad durante la pandemia por COVID-19. Rev Soc Esp Dolor. 2020;27(3): 192-215
Correspondencia: Víctor Mayoral Rojals victormayoral@mac.com 
specific treatments, as well as its mechanism of air transmission and contact with mucous membranes, including asymptomatic individuals. The need for protection on the population and its health professionals requires the establishment of exposure and prevention protocols. One of the new situations generated is the need for a safe return to normal healthcare activities, which in many cases are specific to each specialty.

Objective: To elaborate a document of clinical and management recommendations to guide managers and staff of pain units on how to face the staggered return to normal care with the best available evidence. The document takes into account the safety of patients and professionals in the context of the SARS-CoV-2 pandemic, although we recognize that the changing environment may change the recommendations in the near future.

Methodology: After a narrative review of the literature on PubMed, Google Scholar, and recommendations of competent authorities and scientific societies, The Spanish Pain Society published a first document (V1.0) on April 21 2020 into its WEB (www.sedolor. es), which was shared with the members of the society as well as the presidents of the Spanish autonomous pain societies, leaving open the possibility for improvement through an email posicionamiento.covid.sed@ sedolor.es, where suggestions have been received up to Version 2.1 published on May 13 ${ }^{\text {th }}, 2020$. Some partners have also addressed the board of directors directly and their contributions have also been evaluated and incorporated when possible. This document is based on this latest version.

Results: The document offers a series of general recommendations and others adapted to the different healthcare settings, from telematic assistance to the organization of physical consultation spaces, hospital care, interventional rooms and operating theaters. The recommendations cover from the hygienic measures and protection, to the diagnosis of the disease, risk categorization, the potential modifications in the pharmacological options and available analgesic techniques, as well as an accompanying document to the informed consent.

Conclusions: A new healthcare reality is prevailing. This reality not only goes through security standards adapted to the contagiousness and other consequences of the virus, but also a new healthcare model that incorporates telematic tools with technological security and an adequate legal framework. The deleterious biological and psychological consequences of the virus on pain patients have not yet been fully clarified, so we must be vigilant, preventing and treating this possibility.

Key words: COVID-19, SARS-CoV-2, coronavirus, pain units, preventive measures, Spanish Pain Society, sanitary de-escalation. y de tratamientos específicos, y de un mecanismo de transmisión por vía respiratoria y contacto con mucosas y proximidad entre los individuos, incluso asintomáticos. La necesidad de protección sobre la población y sus profesionales sanitarios obliga a establecer protocolos de control y prevención de exposiciones. Una de las nuevas situaciones generadas es el restablecimiento de la actividad asistencial en condiciones de seguridad, que en muchos casos son específicas de cada especialidad.

Objetivo: Elaborar un documento de recomendaciones clínicas y de gestión que oriente a los gestores y personal asistencial de las unidades de dolor sobre cómo afrontar el retorno escalonado a la labor asistencial con la mejor evidencia disponible. El documento tiene en cuenta la seguridad de los pacientes y profesionales en el contexto de la pandemia por SARS-CoV-2, aunque reconocemos que el entorno cambiante puede modificar en un futuro cercano las recomendaciones.

Metodología: Tras una revisión narrativa de la literatura en PubMed, Google Scholar, y recomendaciones de autoridades competentes y sociedades científicas, la Sociedad Española del Dolor publicó un primer documento (V1.0) el 21 de abril del 2020 en su web (www.sedolor. es) que fue compartido con los socios y presidentes de las sociedades autonómicas de dolor, dejando abierta la posibilidad para su mejora a través de un correo (posicionamiento.covid.sed@sedolor.es), donde se han recibido sugerencias hasta la Versión 2.1, publicada el 13 de mayo de 2020. Algunos socios también se han dirigido directamente a la junta directiva y sus aportaciones han sido asimismo evaluadas e incorporadas cuando ha sido posible. El presente documento está basado en esta última versión.

Resultados: El documento ofrece una serie de recomendaciones generales y otras adaptadas a los diferentes entornos asistenciales, desde la asistencia telemática a la organización de los espacios físicos de consulta, como la atención hospitalaria, las salas de técnicas o el quirófano. Las recomendaciones contemplan desde las medidas higiénicas y protección al diagnóstico de la enfermedad, la categorización del riesgo, las modificaciones en las opciones farmacológicas y técnicas analgésicas disponibles, así como un documento de acompañamiento al consentimiento informado.

Conclusiones: Una nueva realidad asistencial se está imponiendo. Esta realidad no solo pasa por unos estándares de seguridad adaptados a la contagiosidad y otros efectos del virus, si no también a un nuevo modelo asistencial que incorpore las herramientas telemáticas con seguridad tecnológica y un adecuado marco legal. Las secuelas biológicas y psicológicas deletéreas del virus sobre los pacientes con dolor aún no han sido esclarecidas plenamente por lo que debemos estar atentos, previniendo y tratando dicha posibilidad.

Palabras clave: COVID-19, SARS-CoV-2, coronavirus, unidades de dolor, medidas preventivas, Sociedad Española del Dolor, desescalada sanitaria. 


\section{INTRODUCCIÓN Y JUSTIFICACIÓN}

La Organización Mundial de la Salud declaró la enfermedad COVID-19 como pandemia global el 11 de marzo del 2020.

La COVID-19 es principalmente una enfermedad respiratoria aguda (aunque puede afectar a otros órganos de manera severa] causada por un nuevo coronavirus [SARS-CoV-2], identificado por primera vez en diciembre de 2019 en Wuhan (China), y que se ha propagado por todo el mundo a una velocidad inusitada. Este es un nuevo tipo de coronavirus; no estaba identificado previamente en humanos, por lo que la información médica relativa a su control y tratamientos es limitada y se está descubriendo día a día con la experiencia que van adquiriendo los profesionales sanitarios.

La COVID-19 es una enfermedad que cursa en el $80 \%$ de los casos de forma leve o moderada, el $15 \%$ precisa ingreso hospitalario y el $5 \%$ cuidados intensivos. Esta distribución de la gravedad clínica se observó en las primeras series de casos en China, al final de su epidemia, y se ha repetido en los países europeos $[1,2]$.

Aunque se desconoce la prevalencia real, ya que los métodos de detección y diagnóstico han ido evolucionando en estos meses, según los datos oficiales de la CEE, a 26 de mayo la prevalencia de la enfermedad (casos confirmados mediante PCR) en España es de 503,8 casos/100.000 habitantes, con una mortalidad de 57,4 casos/100.000 habitantes [3].

Las siguientes recomendaciones tienen como objetivos la progresiva normalización de la actividad en el entorno asistencial de las unidades de dolor de España y maximizar la protección de los pacientes y el personal que trabaja en ellas.

Se tienen en cuenta unas premisas, consecuencia de las siguientes incertidumbres:

- Desconocemos con seguridad si la inmunidad adquirida es suficientemente protectora y cuánto tiempo lo sería.

- Se ha comunicado un aumento de la morbimortalidad perioperatoria de los pacientes quirúrgicos con infección por SARS-CoV-2 (COVID-19), ya sea conocida preoperatoriamente o no conocida y desarrollada en el postoperatorio. No tenemos la seguridad que las técnicas analgésicas mínimamente invasivas se comportarían de la misma manera [4].

- Conocemos que la sensibilidad y especificidad de las pruebas diagnósticas (PCR/Ac totales/lgG/ IgM) no son concluyentes (ni en combinación) al $100 \%$, y además van a depender de la fase de la enfermedad y la rentabilidad de las muestras.

- Desconocemos con seguridad la influencia de la medicación analgésica sobre la capacidad de variar el pronóstico de la enfermedad activa o la predisposición a padecerla sintomáticamente

- No tenemos una clara explicación para entender por qué un porcentaje bajo (probablemente $<6 \%$ ) de los pacientes que han sufrido la enfermedad y han dado negativo en la prueba de PCR, vuelven a desarrollar síntomas y se positivizan de nuevo ¿¿recaída?, ¿reinfección?, ¿baja sensibilidad de la prueba o la muestra?]
No existen referencias ni experiencias de cómo acometer la normalización asistencial y si los procesos previamente establecidos son igual de válidos y seguros para los pacientes y el personal sanitario en sus diferentes niveles.

Recientemente, la CEE ha dado unas directrices a los estados miembros para la desescalada de la crisis (Hoja de ruta común europea para el levantamiento de las medidas de contención de la COVID-19 [5]) y que todos, gestores y profesionales sanitarios deberemos tener en cuenta. La hoja de ruta tiene en cuenta una desescalada asimétrica, tanto para pacientes como a profesionales, en función de la predisposición a sufrir complicaciones. Como es lógico, la infectividad puede ser bidireccional paciente/sanitario y viceversa, por lo que buena parte de las recomendaciones, incluidas las pruebas serológicas y de PCR, aplican también a todo el personal administrativo y sanitario.

Adicionalmente el periodo de paralización de la actividad asistencial programada está generando una lista de espera de visitas y procedimientos que precisan ser reincorporados al proceso asistencial con el menor perjuicio posible para los pacientes, su calidad de vida, la calidad asistencial y la seguridad laboral.

Por tanto, va a ser necesario un periodo, más o menos largo, de implementación de un modelo asistencial adaptado a la Pandemia COVID-19 y sus consecuencias (6). Este modelo, con probabilidad asimétrica entre zonas de mayor o menor prevalencia, y perfiles asistenciales de las diferentes unidades de dolor, hace que las recomendaciones del presente documento se deban adaptar localmente, siempre de acuerdo con las direcciones médicas, gerencias asistenciales, directrices del Gobierno, colegios profesionales y entidades aseguradoras de pacientes y profesionales.

Sirvan, por tanto, estas recomendaciones para dar una orientación hasta que se cumplan tanto estos condicionantes descritos como se esclarezcan las premisas iniciales.

\section{CONSIDERACIONES ÉTICAS EN DOLOR CRÓNICO Y COVID-19}

La pandemia COVID-19, provocada por el virus SARS-CoV-2, obliga a considerar cuáles han de ser los principios de índole ético que han de guiar las decisiones tomadas para respetar los derechos de todos los ciudadanos y de los pacientes, especialmente en las situaciones más comprometidas.

Estamos en una situación de emergencia en la que quizás las cosas que haríamos habitualmente deben ser matizadas y adaptadas. Así, siendo una situación crítica en varios aspectos, debemos considerar como necesaria la asistencia integral de enfermos con dolor crónico con COVID-19 y familiares relacionados, orientada a la atención de todas las dimensiones que conforman a la persona, porque todas ellas de igual modo quedan afectadas por la enfermedad. No podemos centrarnos en atender solo la dimensión biológica, sino que también se precisa atender las dimensiones espiritual, psicológica, intelectiva-emotiva, social y familiar. 
No podemos olvidarnos de aquellas cuestiones que, en la soledad y al final de la vida, vienen a ser las más importantes de la existencia. El acompañamiento del enfermo y sus familiares en este momento se convierte en necesidad a nivel individual y colectivo.

La enfermedad, sobre todo si es grave, afecta a la persona en su totalidad. El hombre, por ser una unidad psicofísica, unidad dual cuerpo-mente, cuando enferma se resiente todo él. La enfermedad no afecta solamente al cuerpo, sino a toda la persona, en todas sus dimensiones que la definen. Al recomendar la asistencia integral al enfermo no se minusvalora, en absoluto. Todo enfermo tiene derecho a ser respetado y atendido en sus demandas y necesidades de orden psicológico y espiritual.

Sería bueno recordar que los criterios y protocolos de asignación y priorización de recursos deben aplicarse de forma genérica para evitar la variabilidad de resultados, y favorecer la mayor probabilidad de alcanzar los objetivos o resultados favorables posibles, aunque la aplicación debe adaptase de forma individualizada. Ningún protocolo de priorización puede evitar la reflexión y deliberación ética en una toma de decisiones trágica, con recursos escasos y en contexto de máxima tensión. Por eso se recomienda contar con los Comités de Ética Asistencial (CEA) en comisiones permanentes de COVID, para ayudar a la toma de decisiones individualizadas, aunque se sigan criterios de protocolos y recomendaciones, y a prevenir o resolver conflictos de valores.

Debemos expresamente corregir expresiones ambiguas. Las referencias a "supervivencia libre de discapacidad por encima de supervivencia aislada" o "cualquier paciente con deterioro cognitivo, por demencia u otra enfermedad degenerativa, no sería subsidiario de tratamientos invasivos", son incompatibles con la Convención Internacional de Derechos de las Personas con Discapacidad. En una sociedad democrática, la titularidad de derechos no puede estar ligada a la posesión o no de un determinado nivel de conocimientos, habilidades o competencias (una presunta "utilidad social"), sino a la condición de persona.

$Y$ en lo que atañe a los pacientes con dolor crónico difícil, debemos recordar que en la toma de decisiones nuestra obligación moral es buscar el interés de todos los pacientes, no solo los enfermos por COVID-19. El sistema de salud tiene el mismo deber de atender a los pacientes con dolor difícil, que en esta situación de cuarentena se han visto privados de los recursos necesarios para hacer su vida algo más llevadera.

\section{MATERIAL Y MÉTODOS}

Tras una revisión narrativa de la literatura en PubMed y Google Scholar, y de las recomendaciones de autoridades competentes nacionales e internacionales sanitarias y sociedades científicas, la SED publicó un primer documento (V1.0) el 21 de abril del 2020 que fue compartido con los socios y presidentes de las sociedades autonómicas de dolor, dejando abierta la posibilidad para su mejora a través de un correo electrónico [posicionamiento.covid.sed@sedolor.es], donde se han recibido sugerencias hasta la Versión 2.1, publicada el
13 de mayo de 2020. Algunos socios también se han dirigido directamente a la junta directiva y sus aportaciones han sido también evaluadas e incorporadas cuando ha sido posible. El presente documento está basado en esta última versión.

\section{NORMAS GENERALES}

Diversos documentos oficiales (7-14) han sido consultados para realizar unas normas generales. Cuando ha sido posible, se han apoyado las recomendaciones en estudios como revisiones sistemáticas y metanálisis.

Estas normas generales solo representan unas normas básicas que se aconseja se instauren sistemáticamente en las unidades de dolor. La explicación detallada de las mismas, así como otras más específicas, se detallan en el resto del texto.

- Siempre que sea posible se intentará atender a los pacientes por vía telemática, idealmente con videollamada. El paciente debe autorizar este tipo de asistencia y se deben observar los aspectos medicolegales incluidos en la Ley de Autonomía del Paciente y la Ley de Protección de Datos.

- La priorización entre pacientes urgentes, preferentes y diferibles serán definidos por cada unidad de dolor y de acuerdo con la dirección médica del centro.

- Los pacientes COVID + conocidos y con capacidad de contagio seguirán un circuito diferente de acuerdo con las normas de cada centro.

- La asistencia presencial, aunque sea a costa de disminuir el número de pacientes que podrán ser atendidos, se deberá hacer con la mayor agilidad posible y así minimizar el tiempo de espera en salas, en consultas o salas de procedimientos.

- Como norma general se mantendrá una distancia de seguridad mínima de dos metros entre las personas.

- Se aconseja restringir el número de acompañantes a los casos claramente justificados por dependencia del paciente.

- En todos los espacios deberá haber disponibilidad de geles desinfectantes e instrucciones para el lavado de manos.

- La disponibilidad de mascarilla quirúrgicas debe estar asegurada para todos los pacientes en los espacios de la unidad.

- El resto de las medidas higiénicas y de protección, dependiendo del entorno asistencial, están esquematizadas en los Anexos 1 a 4.

- Se recomienda mostrar las normas de protección por medios audiovisuales, tanto en las salas de espera como las de valoración y tratamiento.

- Se priorizarán los tratamientos farmacológicos (ver apartado) y de rehabilitación no presencial $(15,16)$, a ser posible con ejercicios dirigidos mediante ayuda de medios audiovisuales.

- Reforzar mensajes para optimizar una correcta dieta, ergonomía y sueño.

- El enfoque biopsicosocial del dolor incluye el tratamiento psicológico (17-20). 


\section{EVOLUCIÓN CLÍNICA DE LA ENFERMEDAD E INMUNIDAD ADQUIRIDA}

La Figura 1 resume las diferentes fases y escenarios más probables para la COVID-19 [21].

El Centro Europeo para la Prevención y el Çontrol de Enfermedades (ECDC) ha publicado un informe [२२] donde se esclarecen la mayoría de estos escenarios.

En este informe el ECDC considera que, con la información disponible actualmente, el periodo medio de incubación de la enfermedad es de 5 a 6 días, con un rango de 1 a 14 días. Se estima que la contagiosidad comienza a partir de 2,3 días (IC del $95 \%$, 0,8 a 3,0 días) antes del inicio de los síntomas y alcanza su punto máximo a los 0,7 días (IC del $95 \%,-0,2$ a 2,0 días) antes del inicio de los síntomas. En un análisis de datos de una cohorte de pacientes con COVID-19 y un metanálisis de hallazgos de publicaciones, se detectó ARN viral en muestras de heces del 48,1 \% (IC 95\%, 38,3-57,9\%) de los pacientes, incluso en heces recolectadas después de que las muestras respiratorias dieran negativo. Cabe señalar que la detección de ARN viral por PCR no equivale a la infectividad, a menos que las partículas de virus infecciosos se hayan confirmado a través del aislamiento del virus y se hayan cultivado de las muestras particulares. En un estudio retrospectivo de 113 pacientes sintomáticos, la mediana de la duración de la detección de ARN del SARS-CoV-2 fue de 17 días (Inter Intercuartil [RI], 13-22 días), medida desde el inicio de la enfermedad. Al comparar pacientes con eliminación temprana de ARN viral $[<15$ días] y tardía ( $\geq 15$ días después del inicio de la enfermedad), la diseminación prolongada de SARSCoV-2 se asoció con el sexo masculino ( $p=0,009$ ), mayor edad ( $p=0,033$ ), hipertensión ( $p=0,009)$, ingreso tardío al hospital después del inicio de la enfermedad $(p=0,001)$, enfermedad grave al ingreso $(p=0,049)$, ventilación mecánica invasiva $(p=0,006)$ y tratamiento con corticosteroides ( $p=0,025)$. Los pacientes con una mayor duración del periodo de diseminación tuvieron una recuperación más lenta de la temperatura corporal ( $p<0,001$ ) y absorción focal en las imágenes radiográficas ( $p<0,001$ ) que los pacientes con una eliminación temprana del ARN del SARS-CoV-2.

Aún no se han establecido correlaciones definitivas entre el grado de protección para COVID-19 y la detección de anticuerpos contra el SARS-CoV-2. Así, la mera detección de anticuerpos no indica con seguridad inmunidad de protección directa, especialmente si no se ha utilizado un ensayo de neutralización como método de detección. Según los datos disponibles actualmente, los anticuerpos IgM e IgG contra el SARS-CoV-2 se desarrollan entre 6 y 15 días después del inicio de la enfermedad. La mediana del tiempo de seroconversión para los anticuerpos totales (Ab), IgM y luego lgG fueron los días 11, 12 y 14 después del inicio de los síntomas, respectivamente. La presencia de anticuerpos se detectó en < $40 \%$ entre los pacientes dentro de una semana desde el inicio, y aumentó rápidamente al $100 \%$ (Ab total), 94,3 \% (lgM) y 79,8 \% (lgG) desde el día 15 después del inicio. Es demasiado pronto para saber cuánto durará la respuesta inmune protectora contra el SARS-CoV-2, ya que esto requerirá estudios serológicos longitudinales que sigan la inmunidad de los pacientes durante un periodo prolongado de tiempo. La posibilidad de reinfección y la duración de la inmunidad aún no se han estudiado. Se demostró que la infección primaria con SARS-CoV-2 protege a los macacos rhesus del desafío posterior y arroja dudas sobre los informes de que la positividad observada en los pacientes dados de alta se debe a la reinfección.

\section{TEST DIAGNÓSTICOS}

Las siguientes recomendaciones se aconsejan tanto para el paciente como para el personal sanitario.

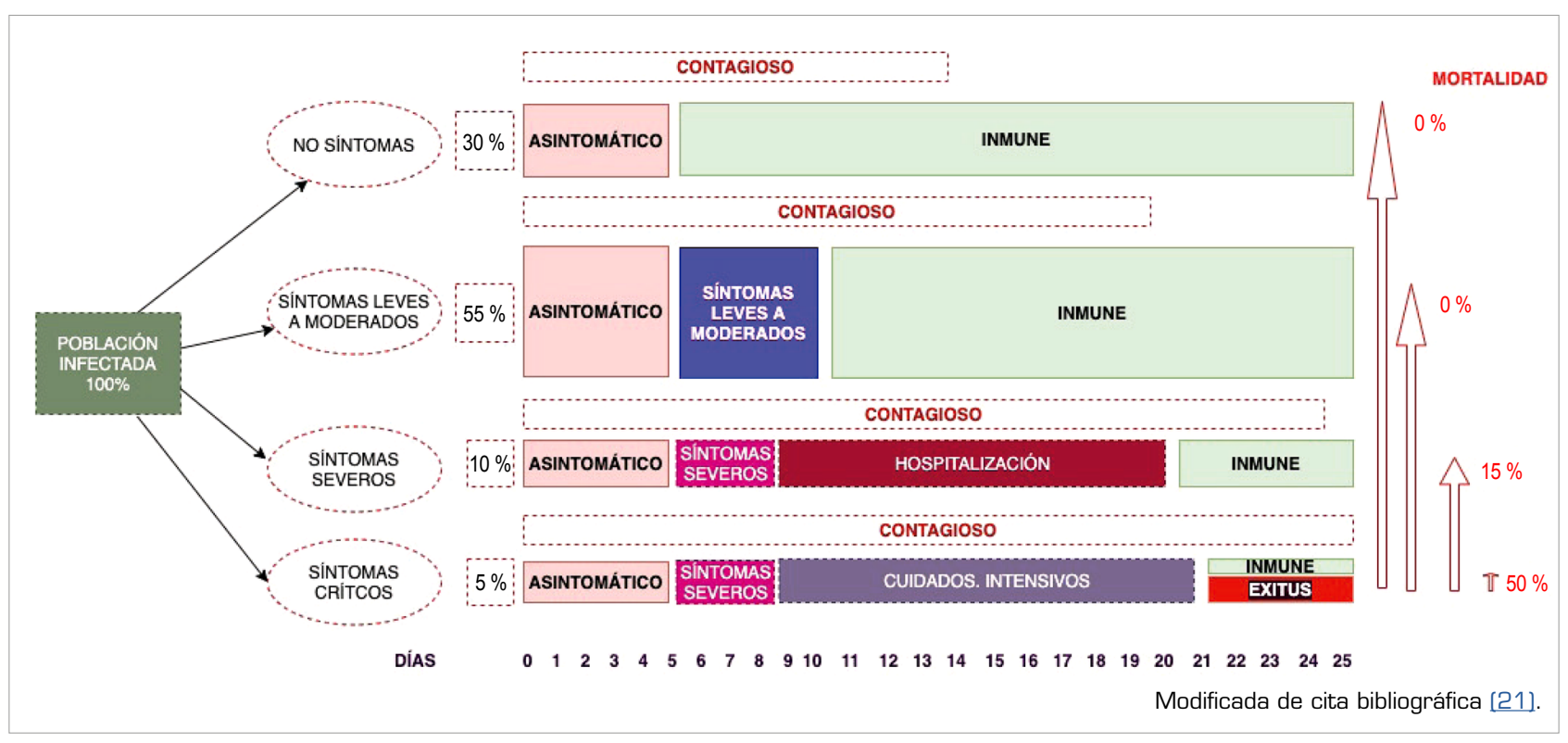

Fig. 1. Resumen evolutivo de la enfermedad COVID-19. 
TABLA I

RESULTADOS DE LA DETECCIÓN DE LA RT-PCR EN DIFERENTES MUESTRAS.

\begin{tabular}{|l|c|}
\hline \multicolumn{1}{|c|}{ Tipo de muestra } & Positiva [\%] \\
\hline Lavado broncoalveolar & $93 \%$ \\
\hline Cepillado bronquial & $46 \%$ \\
\hline Esputo & $72 \%$ \\
\hline Hisopos nasales & $63 \%$ \\
\hline Hisopos faríngeos & $32 \%$ \\
\hline Heces & $29 \%$ \\
\hline Sangre & $1 \%$ \\
\hline Orina & $0 \%$ \\
\hline
\end{tabular}

Adaptada de cita bibliográfica [24].

La SED aconseja que se hagan todos los esfuerzos posibles para detectar aquellos pacientes y personal SARS-CoV-2 +, sean o no sintomáticos, dado que eso afectará a los circuitos asistenciales y la seguridad de todos.

Extraído de un reciente artículo publicado en JAMA por Sethuraman y cols. (23), debemos tener en cuenta las siguientes conclusiones sobre las pruebas de detección: "Usando la evidencia disponible, se ha diseñado una línea de tiempo clínicamente útil de marcadores de diagnóstico para la detección de COVID-19 (se recomienda consultar la figura de evolución temporal de los diferentes test y las muestras biológicas en las que está presente el virus de la cita bibliográfica 23). La mayoría de los datos disponibles son para poblaciones adultas que no están inmunocomprometidas. El curso temporal de la positividad de la PCR y la seroconversión puede variar en niños y otros grupos, incluida la gran población de individuos asintomáticos que no se diagnostican sin vigilancia activa. Quedan muchas preguntas, particularmente cuánto tiempo dura la inmunidad potencial en individuos, tanto asintomáticos como sintomáticos, que están infectados con SARS-CoV-2".

La rentabilidad y significado de las pruebas va a depender de la fase de la enfermedad, así como de la calidad y procedencia de la muestra (Tabla I).

La rentabilidad de la muestra de RT-PCR (real-time reverse transcriptase] va a depender también de la carga viral, de la zona de extracción y la metodología utilizada.

Así, con el fin de mejorar el diagnóstico y la fase en la que se encuentra el paciente o profesional, la opción más recomendable sería la combinación de PCR para antígeno y un test serológico de anticuerpos, aun siendo conscientes de los problemas de sensibilidad y especificidad de los diferentes test serológicos (25), también dependientes de la prevalencia en la población [26].

El siguiente esquema, publicado en la web del Ministerio de Salud, Consumo y Bienestar Social [27], simplifica la interpretación de las pruebas (Tabla II).

Así, con toda esta información, y teniendo en cuenta la actual evidencia de la contagiosidad en fase asintomática, es altamente recomendable que se asocien las
TABLA II

INTERPRETACIÓN DE LOS RESULTADOS DE TEST DIAGNÓSTICOS DE SARS-COV-2.

\begin{tabular}{|c|c|c|c|c|}
\hline PCR & Ag & IgM & IgG & Interpretación \\
\hline+ & - & - & - & Fase presintomática \\
\hline+ & $+/-$ & $+/-$ & $+/-$ & Fase inicial [aprox. 1-7 dias] \\
\hline$+/-$ & - & + & $+/-$ & 2. $^{\text {a }}$ Fase [8-14 días] \\
\hline$+/-$ & - & ++ & ++ & 3. $^{\text {a }}$ Fase $>15$ días \\
\hline- & - & $+/-$ & ++ & Infección pasada (inmune] \\
\hline
\end{tabular}

pruebas diagnósticas a los métodos clínicos de cribaje basados en antecedentes, síntomas y signos. Esto es especialmente importante en situaciones de riesgo de exposición o tratamientos que podrían cambiar el curso de la enfermedad (ver siguiente apartado de circuito asistencial, y Anexos 4 y 5). También se recomienda consultar con los servicios de salud preventiva, así como servicios de enfermedades infecciosas, inmunología y microbiología de cada centro a la hora de diseñar protocolos locales.

En el caso de que el paciente sea candidato para realizar una PCR previa a un tratamiento en la unidad de dolor, se le pedirá guardar confinamiento desde la realización de la PCR hasta el procedimiento para disminuir razonablemente el contagio durante el periodo ventana.

Para un manejo adecuado de las muestras y observar la evolución de las recomendaciones, se recomienda consultar la página de la OMS [28].

\section{CIRCUITO ASISTENCIAL}

Los profesionales de las unidades de dolor ofrecen su asistencia en diferentes espacios, desde la consulta, los quirófanos, hospitales de día, salas de hospitalización y salas de técnicas o radiología. Los diferentes espacios asistenciales deben asegurar el cumplimiento de las normas generales y también las peculiaridades de cada uno aquí detalladas. El ministerio ha publicado normas que nos ayudarán a su implantación, ofreciendo la mejor seguridad posible. Dichas normas están más orientados a entornos quirúrgicos, pero el Ministerio está trabajando en un nuevo documento especialmente para salas de intervencionismo con diferentes sociedades, incluida la SED $(4,8)$.

- Triaje clínico de los pacientes antes de acudir a la unidad; una vez en ella:

- En esta fase de desescalada, y teniendo en cuenta las premisas iniciales, debemos ponderar el riesgo/beneficio de hacer acudir a un paciente a la unidad y, si es necesario, ofrecer las mejores garantías de protección para él, el resto de los pacientes y el personal sanitario.

- Además de las pruebas de detección de virus o su respuesta inmunológica, más indicadas para ciertos procedimientos intervencionistas o en íntimo contacto con la vía aérea, las herramientas clínicas de triaje son esenciales para categorizar 
a los pacientes por riesgo y tomar decisiones en consecuencia. Siempre incluirán criterios clínicos con valoración de comorbilidades, síntomas, signos y antecedentes de exposición al virus. Los criterios analíticos (hemograma, LDH, PCR, IL-6, ferritina...) y radiológicos (Rx tórax/ TAC torácico], se consideran opcionales y com- plementarios en caso de duda diagnóstica y para procedimientos que lo requieran.

- Síntomas y signos: aconsejamos realizar las siguientes preguntas, primero por vía telemática y de nuevo en la recepción del paciente en áreas de la unidad de dolor, si el paciente debe acudir (Figura 2) (29).

CHECK LIST COVID 19 - SOCIEDAD ESPAÑOLA DEL DOLOR

\section{SEDQ}

NOMBRE

¿HA TENIDO EN LAS 2 ULTIMAS SEMANAS ALGUNO DE LOS SIGUIENTES SINTOMAS?

Fiebre

Tos seca y persistente

Astenia (debilidad o fatiga)

Expectoración (expulsión de flemas)

Disnea (dificultad para respirar)

Dolor de garganta

Cefalea (dolor de cabeza)

Mialgia o artralgia (dolor de las articulaciones)

Escalofíos

Náuseas o vómitos

Congestión nasal

Diarrea

Hemoptisis (tos con sangre)

Congestión conjuntival

Perdida olfato y/o gusto

Manchas o erupciones en piel

HA SIDO DIAGNOSTICADO DE COVID?

Si ¿Cuando?

No

SOLO PARA INTERVENCIONISMO (A RELLENAR POR

EL PERSONAL SANITARIO)

PUNTUACION INDICE ASIPP

Fig. 2. Lista de verificación (check list) clínico de la enfermedad COVID-19. 
- Comorbilidades: interrogaremos sobre la edad, patología pulmonar, cardiovascular, obesidad, diabetes, renal, hepática e inmunodeficiencia. La American Society of Interventional Pain Physycians (ASIPP) ha publicado una escala que estratifica el riesgo basado en estas variables (30), adaptado al castellano (31), y que consideramos muy útil, sobre todo para planificar intervencionismo en dolor (Figura 3). Las tres categorías de riesgo nos orientarán sobre la conveniencia de la indicación de la técnica basándose en la probabilidad potencial de una evolución desfavorable del paciente en el caso de contagiarse y enfermar.

- Existen otros recursos de ayuda disponibles para el triaje, como la herramienta triage COVID-19 [32], que valoramos de utilidad.

- Consultas (primera y sucesivas):

- Asistencia telemática en primera opción, siempre que sea posible, sobre todo en pacientes de riesgo. Este tipo de asistencia idealmente debe incluir no solo la entrevista con el paciente sino también la revisión de pruebas pedidas. Se facilitarán mecanismos para que la disponibili-

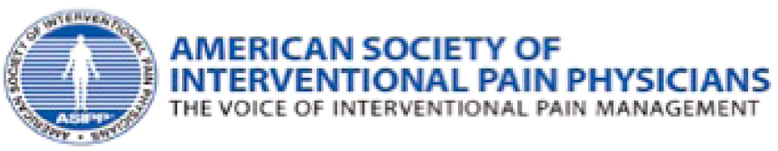

\section{Adaptación SED de la Estratificación de riesgo ASIPP para pacientes candidatos a procedimientos intervencionista}

Si el paciente vive en una residencia de ancianos considérelo como paciente de ALTO RIESGO.

Si no, siga la siguiente tabla de estratificación de riesgos.

\begin{tabular}{|c|c|c|c|c|}
\hline Factor de riesgo & Bajo riesgo & Riesgo moderado & Riesgo alto & Comentarios \\
\hline Edad (años) & $\begin{array}{l}45-64 \\
\text { (1) }\end{array}$ & $\begin{array}{l}\text { 65-74 } \\
\text { (2) }\end{array}$ & $\begin{array}{c}>=75 \\
\text { (3) }\end{array}$ & \\
\hline Pulmonar & $\begin{array}{l}\text { Ninguno } \\
\text { (0) }\end{array}$ & $\begin{array}{l}\text { Asma intermitente } \\
\text { de baja severidad } \\
\text { (२) }\end{array}$ & $\begin{array}{l}\text { Enfermedad obstructiva crónica } \\
\text { (Ej.: asma moderado a severo, } \\
\text { EPOC-Bronquitis crónica) } \\
\text { (3) }\end{array}$ & \\
\hline Cardiovascular & $\begin{array}{l}\text { Ninguno } \\
\text { (O) }\end{array}$ & $\begin{array}{l}\text { HTA o Cl } \\
\text { (2) }\end{array}$ & $\begin{array}{c}\mathrm{HTA}+\mathrm{Cl} \\
\mathrm{HTA}+\mathrm{ICC} \\
\mathrm{HTA}+\mathrm{Cl}+\mathrm{ICC} \\
\text { ICC aislada } \\
\text { (3) }\end{array}$ & \\
\hline Obesidad & $\begin{array}{c}\text { IMC 24.9-29.9 } \\
\text { (1) }\end{array}$ & $\begin{array}{c}\text { IMC 30.0-39.9 } \\
\text { (2) } \\
\end{array}$ & $\begin{array}{c}\mathrm{IMC}>=40 \\
(3)\end{array}$ & \\
\hline $\begin{array}{l}\text { Diabetes (HbA1C) } \\
\text { (Glicemia mg/dl) }\end{array}$ & $\begin{array}{c}5.7-6.49 \mathrm{o} \\
100-120 \mathrm{mg} / \mathrm{dl} \\
\text { (1) }\end{array}$ & $\begin{array}{c}6.50-8.49 \mathrm{o} \\
120-160 \mathrm{mg} / \mathrm{dl} \\
\text { (2) }\end{array}$ & $\begin{array}{c}>=8.50>160 \mathrm{mg} / \mathrm{dl} \\
\text { (3) }\end{array}$ & $\begin{array}{l}\text { Considerar glicemia } \\
\text { capilar si no se } \\
\text { dispone }\end{array}$ \\
\hline Renal & $\begin{array}{l}\text { Ninguno } \\
\text { (O) }\end{array}$ & $\begin{array}{l}\text { IRA o IRC } \\
\text { (ट) }\end{array}$ & $\begin{array}{c}\text { Diálisis } \\
\text { (3) }\end{array}$ & \\
\hline Hepática & $\begin{array}{l}\text { Ninguno } \\
\text { (O) }\end{array}$ & $\begin{array}{l}\text { Hepatitis crónica } \\
\text { (२) }\end{array}$ & $\begin{array}{l}\text { Cirrosis } \\
\text { (3) }\end{array}$ & \\
\hline Inmunosupresión & $\begin{array}{l}\text { No } \\
\text { (O) }\end{array}$ & $\begin{array}{l}\text { Una patología } \\
\text { estable } \\
\text { (२) }\end{array}$ & $\begin{array}{l}\text { Presencia de alguna de las } \\
\text { - Cáncer (tratamiento activo) } \\
\text { - Trasplante } \\
\text { - Inmunodeficiencias } \\
\text { - HIV/SIDA mal controlado } \\
\text { - Uso crónico de esteroides } \\
\text { (3) }\end{array}$ & \\
\hline
\end{tabular}

** El número de puntuación para el factor de riesgo aparece entre paréntesis. Este número indica los puntos para esa condición.

- Bajo riesgo: < = 7 puntos... realizar la técnica teniendo en cuenta las recomendaciones sobre corticoides más adelante explicadas.

- Riesgo moderado: 8-14 puntos... realizar la técnica en base a criterios individuales de riesgo/beneficio.

- Riesgo alto: > = 15 puntos... retrasar la intervención a menos que sea urgente.

Fig. 3. Adaptación SED al español de la Estratificación de riesgo ASIPP para pacientes candidatos a procedimientos de dolor intervencionista. 
dad de las pruebas por medios telemáticos sea un hecho en los entornos donde aún no esté implementado.

- En esta etapa se aconseja limitar la consulta presencial a casos preferentes que no se puedan solucionar por vía telemática, por ejemplo: I Dolor oncológico no controlado.

I Cualquier dolor severo con signos de alarma.

I Neuralgia postherpética.

I Neuralgias craneofaciales.

I Otras neuralgias de alta intensidad.

I Síndrome de dolor regional complejo.

I Radiculalgia aguda de inicio brusco o empeoramiento de radiculalgia previa.

Si se ha hecho un trabajo previo telemático, esta consulta presencial requerirá menos tiempo y disminuirá el riesgo de contagio.

Seguir las recomendaciones de los Anexos 1 y 2 para los niveles de protección del paciente, personal administrativo y sanitario.

- Por lo que respecta a la prescripción de medicamentos con receta electrónica, actualmente es posible por vía telemática en la mayoría de los servicios de salud. Una alternativa, si esta no se encuentra disponible, son las plataformas habilitadas por varios colegios de médicos y farmacéuticos $[33,34]$.

La prescripción de opioides, cuando precise de receta de estupefacientes, es un requisito legal de difícil solución telemática en la medicina privada, por lo que se deberá cumplimentar en papel y recogerse en consulta por un familiar o enviarse por correo postal.

- En caso de sordera del paciente, se pueden seguir las recomendaciones que se recogen en las asociaciones de personas sordas (35).

- Planta de hospitalización:

- Las interconsultas en pacientes hospitalizados seguirán las normas de cada centro, pero como orientación general, se recomienda el nivel de protección descrito en el Anexo 2.

- También valorar si la interconsulta puede ser resuelta mediante contacto con su médico responsable, en caso de que el paciente no esté ingresado por la unidad de dolor.

- Técnicas analgésicas:

- La indicación de una técnica analgésica preferente se hará en base a una valoración individual y la cartera de servicios de la unidad de dolor.

- En la fase actual de la pandemia, ante la decisión de proceder o no a realizar una técnica intervencionista, se recomienda utilizar en esta fase de desescalada la herramienta de estratificación de riesgo por comorbilidad ASIPP mostrada en el apartado de comorbilidades, para ponderar el grado de urgencia de la indicación, aunque siempre debe prevalecer el criterio del médico tras haber informado adecuadamente al paciente sobre los riesgos potenciales:

I Riesgo bajo: realizar la técnica teniendo en cuenta las recomendaciones sobre corticoides más adelante explicadas.

I Riego moderado: realizar la técnica en base a criterios individuales de riesgo/beneficio.
I Riesgo alto: retrasar la intervención a menos que sea urgente.

- Las siguientes se consideran intervenciones o técnicas preferentes:

I Recambio o relleno de una bomba intratecal, en especial si el paciente sigue tratamiento con baclofeno (urgente) y/o clonidina $u$ opioide (preferente, en especial si no disponemos de alternativa farmacológica).

I Retirada de un sistema implantado infectado (urgente).

I Técnicas para dolor oncológico con alto beneficio/riesgo.

I Técnicas de radiofrecuencia para neuralgias craneofaciales severas no controladas con medicación.

I Neuralgias deficitarias.

- No todas las técnicas analgésicas van a tener el mismo riesgo de exposición, y como tal van a necesitar diferentes grados de cribaje preoperatorio y protección intraoperatoria. Los factores determinantes conocidos son:

I Procedimiento quirúrgico invasivo vs. mínimamente invasivo (ejemplo: percutáneo).

I Duración del procedimiento.

I Órgano diana cercano a la vía aérea.

I Posición del paciente.

I Necesidad potencial o real de aerosoles.

I Necesidad de sedación que precise un potencial manejo de la vía aérea.

- Los autores de estas recomendaciones creen que se deben tratar todas las técnicas con el mismo nivel de protección, reflejados en el Anexo 3.

- En los Anexos 4 y 5, se pueden consultar los esquemas de las distintas opciones y precauciones del circuito asistencial en una unidad de dolor.

\section{ATENCIÓN DIFERENCIADA A LOS PACIENTES COVID-19 [+] Y CONTAGIOSOS}

En estos pacientes deberemos ponderar individualmente la conveniencia de retrasar el tratamiento o la valoración clínica a menos que sea urgente. Debemos tener en cuenta las posibles interacciones de los fármacos de uso en COVID-19 con los analgésicos (ver apartado de fármacos). En cuanto a intervenciones urgentes relacionadas con el dolor, las que se consideran no demorables en este tipo de pacientes COVID + son las indicadas por infección de un dispositivo implantado y un recambio de bomba intratecal por agotamiento de batería en un paciente en tratamiento con baclofeno (en menor medida en tratamiento con clonidina y/o opioides, siempre que no haya tratamiento sustitutivo). En el caso de tenerse que realizar una consulta presencial y/o tratamiento, se realizarán las pruebas preoperatorias necesarios (ver Anexo 4 y apartado "Test"). Otras sociedades, como la SEDAR, han realizado unas guías que nos serán de utilidad para el manejo intraoperatorio en estos casos (36). Las recomendaciones del Centro Europeo para el Control de Enfermedades se actualizan con frecuencia también (37). 


\section{OBTENCIÓN DEL CONSENTIMIENTO INFORMADO}

En este contexto, el requisito legal de la obtención de un consentimiento informado para técnicas analgésicas deberá incluir un apartado informativo de los riesgos específicos asociados a la nueva situación, con las incertidumbres que tenemos y debemos compartir con el paciente. Se seguirán las recomendaciones del colegio de médicos al que pertenezca el profesional y se recomienda consultar con el seguro de responsabilidad civil en el caso de que se opte por consentimientos no presenciales [existen plataformas disponibles para ello]. La información sobre el tratamiento debe ser dada con anterioridad al procedimiento y con el suficiente tiempo de reflexión, aconsejándose un mínimo de $24 \mathrm{~h}$. En cualquier caso, recomendamos dejar constancia por escrito de que se informa al paciente de los riesgos y beneficios, que lo entiende y acepta.

En el Anexo 6 se puede consultar el Documento de acompañamiento al consentimiento informado de la SED para técnicas analgésicas invasivas e intervenciones quirúrgicas con finalidades analgésicas.

\section{RIESGOS LABORALES DE PERSONAL ASISTENCIAL Y ADMINISTRATIVO}

El personal sanitario está más expuesto a la infección y la prevalencia de infectados parece superior a la población general (ver apartado "Equipos de protección personal"]. Así, se deberán seguir las recomendaciones del Ministerio observando sus actualizaciones (Procedimiento de actuación para los servicios de prevención de riesgos laborales frente a la exposición al sars-cov- 2 de 8 de abril de 2020 [38] (Figura 4).

En los centros en los que exista un departamento de riesgos laborales, o que esté contratado externamente, se le pedirá que actualice sus normas que deberán estar disponibles para todo el personal. Como orientación rápida para conocer el nivel de protección personal necesario en los diferentes entornos asistenciales, aconsejamos consultar los Anexos 1 a 3 .

Se pueden consultar otras fuentes de información sobre el grado de protección necesaria, que cubren entornos no específicos de las unidades de dolor [39].

Se considera prudente extremar las medidas de protección con todo el personal con mayor riesgo de contraer una complicación grave por COVID-19, tales como inmunodeprimidos, cardiópatas, enfermedades respiratorias crónicas, mayores de 60 años, etc.

\section{USO DE FÁRMACOS ANALGÉSICOS PAUTADOS Y EN TÉCNICAS ANALGÉSICAS INDICADAS [NO SUSCEPTIBLES DE DEMORA TRAS VALORAR RIESGO-BENEFICIO) [40]}

No disponemos de ensayos clínicos que nos puedan aconsejar con certeza sobre la seguridad o preferencia de un fármaco analgésico u otro en este contexto. La

\section{ANEXO IV: GUÍA DE ACTUACIÓN PARA LA GESTIÓN DE LA VULNERABILIDAD Y EL RIESGO EN EL ÁMBITO SANITARIO Y SOCIOSANITARIO}

\begin{tabular}{|c|c|c|c|c|c|c|c|c|c|c|c|c|}
\hline \multirow{2}{*}{$\begin{array}{l}\text { Grupos vulnerables } \\
\text { Exposición laboral }\end{array}$} & \multicolumn{4}{|c|}{ Patología controlada } & \multicolumn{4}{|c|}{ Patología descompensada } & \multicolumn{4}{|c|}{ Comorbilidad $\geq 2$ aspectos } \\
\hline & NR1 & NR2 & NR3 & NR4 & NR1 & NR2 & NR3 & NR4 & NR1 & NR2 & NR3 & NR4 \\
\hline Enfermedad cardiovascular/HTA & 1 & 1 & 2 & 2 & 1 & 3 & 3 & 3 & 1 & 3 & 3 & 3 \\
\hline Diabetes & 1 & 1 & 2 & 2 & 1 & 3 & 3 & 3 & 1 & 3 & 3 & 3 \\
\hline Enfermedad pulmonar crónica & 1 & 1 & 2 & 2 & 1 & 3 & 3 & 3 & 1 & 3 & 3 & 3 \\
\hline Inmunodeficiencia & 1 & 3 & 3 & 3 & 1 & 4 & 4 & 4 & 1 & 4 & 4 & 4 \\
\hline Cáncer en tratamiento activo & 1 & 4 & 4 & 4 & 1 & 4 & 4 & 4 & 1 & 4 & 4. & 4 \\
\hline \multirow[b]{2}{*}{ Mayores de 60 años } & \multicolumn{4}{|c|}{ Sin patología } & \multicolumn{4}{|c|}{ Patología controlada } & \multicolumn{4}{|c|}{ Patología descompensada } \\
\hline & 1 & 1 & 2 & 2 & 1 & 3 & 3 & 3 & 1 & 4 & 4. & 4 \\
\hline \multirow[b]{2}{*}{ Embarazo } & \multicolumn{4}{|c|}{$\begin{array}{c}\text { Sin complicaciones ni } \\
\text { comorbilidades }\end{array}$} & \multicolumn{4}{|c|}{ Con complicaciones o comorbilidades } & & & & \\
\hline & 1 & 3 & 3 & 3 & 1 & 4 & 4 & 4 & & & & \\
\hline
\end{tabular}

NR1 (Nivel de riesgo 1): Similar a riesgo comunitario. Tareas en áreas no COVID, tanto asistenciales como de soporte estratégico.

NR2 (Nivel de riesgo 2): Entrada en zonas COVID tareas con pacientes posibles, probables o confirmados, manteniendo la distancia de seguridad y sin actuación directa sobre paciente, por ejemplo, reparto de comida, limpieza, traslado de pacientes, etc.

NR3 (Nivel de riesgo 3): Entrada en zonas COVID con asistencia directa a pacientes o intervención directa con casos posibles probables o confirmados, con EPI adecuado y sin mantener la distancia de seguridad, incluida la movilización de pacientes y aseo.

NR4 (Nivel de riesgo 4): Profesionales, sanitarios o no sanitarios, que deben realizar maniobras generadoras de aerosoles (RCP, intubación, extubación, etc.).

\begin{tabular}{|c|l|}
\hline 1 & No precisa ni adaptación ni cambio de puesto, permanece en su actividad laboral habitual. \\
\hline 2 & $\begin{array}{l}\text { Continuar actividad laboral. Puede realizar tareas con exposición a pacientes posibles, probables o confirmados por COVID 19, con EPIs } \\
\text { adecuados. No puede realizar maniobras generadoras de aerosoles. }\end{array}$ \\
\hline 3 & Continuar actividad laboral en zona NO COVID. \\
\hline 4 & Precisa Cambio de Puesto de Trabajo y, de no ser posible, tramitar IT como Trabajador Especialmente Sensible o PREL. \\
\hline
\end{tabular}

IT: incapacidad temporal. PREL: prestación riesgo embarazo lactancia.

Fig. 4. Guía de actuación para la gestión de la vulnerabilidad y el riesgo en el ámbito sanitario y sociosanitario. 
mayoría de la literatura se basa en inferencias asumidas como razonablemente válidas por estudios hechos en el contexto de otras enfermedades víricas. A efectos prácticos diferenciaremos entre los pacientes con enfermedad activa y aquellos sin enfermedad o que la han pasado pero que no han desarrollado inmunidad aún.

\section{Pacientes sin inmunidad adquirida con o sin enfermedad activa}

Aunque se están realizando estudios sobre la influencia de los fármacos analgésicos sobre la predisposición a contraer la enfermedad y un hipotético pronóstico diferencial en los que los toman o han sido sometidos a técnicas analgésicas farmacológicas, por el momento desconocemos con seguridad su influencia. Lamentablemente, las recomendaciones siguientes están solo fundamentadas en la interacción de los analgésicos con otras enfermedades víricas, como la gripe por Influen$z a$, de la que tenemos más y mejor evidencia. Los más conflictivos son:

- Corticoides.

- ESRA y ASRA desaconsejan el uso de corticoides a dosis habituales, basándose en estudios previos de casos controles en gripe por Influenza, por lo que, en el caso de tener que utilizarlos, recomiendan la dosis más baja posible y comentan la probable menor duración de la inmunosupresión si se utiliza betametasona o dexametasona (41). Los mecanismos por los que podrían modificar el curso de la enfermedad más probables son tanto el bloqueo de la respuesta hipertérmica, una defensa natural ampliamente comprobada, así como su potencial inmunosupresor $(42,43)$.

- En la misma línea, Shanthanna y cols. (40), así como la Faculty of Pain Medicine of the Royal College of Anaesthetists, instan a la precaución sobre la seguridad de los esteroides inyectados durante la actual pandemia de COVID-19 (44).

- La British Society of Skeletal Radiologists recomienda que se deben evitar las inyecciones intrarticulares de esteroides, tejidos blandos y perineurales durante la pandemia de COVID-19, siempre que sea posible, para reducir el riesgo de inmunidad reducida a la exposición viral 445).

- La Spine Intervention Society ha publicado dos documentos, uno sobre inyecciones epidurales en pacientes inmunodeprimidos (46) y otro específico de corticoides [47]. En el primero concluye que no hay evidencia clara de un efecto causal entre las inyecciones espinales y las infecciones y complicaciones en pacientes inmunodeprimidos; sin embargo, existe la posibilidad de que los esteroides puedan aumentar el riesgo de infección y la administración de corticosteroides debe abordarse con precaución en estos pacientes. En el segundo concluye que hay evidencia de baja calidad de que una sola inyección de corticosteroides intrarticulares puede aumentar el riesgo de contraer el virus de la influenza. Todavía no se ha publicado ningún estudio que examine si una inyección de corticosteroides aumenta el riesgo de contraer COVID-19 o altera el curso clínico de una infección posterior. Si bien se recomienda precaución basada en esta evidencia indirecta, se necesitan más estudios para determinar la correlación completa de la administración de corticosteroides y los riesgos de contraer COVID-19. Se ha demostrado que la dexametasona tiene una duración más corta del efecto sistémico y puede ser favorecida sobre otros esteroides para inyecciones en ciertas circunstancias.

- La recomendación de la SED, y hasta que no se disponga de mayor evidencia, aconseja valorar al paciente individualmente y optar por otras opciones siempre que sea posible, o posponga la inyección hasta que se reduzca el riesgo asociado con esta pandemia. Si hay una indicación que no se pueda demorar y sin alternativa razonable posible, considere el uso de betametasona o dexametasona a las dosis más bajas posibles y en las indicaciones aprobadas.

- Antinflamatorios no esteroideos, paracetamol y metamizol: tras la alerta del ministerio francés de salud sobre el ibuprofeno (48), tanto la SED como la EFIC y la agencia europea EMA ya se posicionaron en contra de esa afirmación (49), pero acaban recomendando el uso de paracetamol. Los autores de estas recomendaciones no han encontrado ningún estudio con evidencia suficiente que pueda ayudar a dar una recomendación específica, pero muestran su preocupación sobre el uso de cualquier fármaco que bloquee la respuesta antitérmica como mecanismo de defensa y alerta.

- Antidepresivos: en el caso que el paciente esté en tratamiento con fármacos para el COVID-19 que alarguen el intervalo QTc, habitualmente bajo ensayo clínico, debemos comprobar que no interaccionen con los antidepresivos (https://www. crediblemeds.org). Por ejemplo, la amitriptilina y la venlafaxina pueden causar la prolongación del intervalo QTc, pero actualmente se carece de evidencia de un riesgo de Torsade de Pointes cuando se toman según la pauta recomendada. Recomendación: monitorizar ECG en caso de asociación o valorar otra alternativa como Duloxetina.

- Opioides:

- Metadona: en el caso que el paciente esté en tratamiento con fármacos para el COVID-19 que alarguen el QTc, habitualmente bajo ensayo clínico, debemos optar por otro opioide que no alargue QTc (https://www.crediblemeds.org).

- La buprenofina y el tramadol pueden causar la prolongación del intervalo QT, pero actualmente se carece de evidencia de un riesgo de Torsade de Pointes cuando se toman según lo recomendado. Recomendación: monitorizar ECG en caso de asociación a tratamiento ant-COVID-19 que alargue el QTc o valorar otra alternativa.

- En cuanto a la potencial inmunosupresión que pueden causar los opioides, una reciente revisión sistemática solo encontró una débil asociación, concluyendo: "Esta revisión sistemáti- 
ca encontró indicios de que el tratamiento con opioides a largo plazo altera el sistema inmunitario en pacientes con dolor crónico no oncológico. Estas alteraciones involucraron las células NK y la producción de IL-1 $\beta$. Sin embargo, el nivel de evidencia es débil”. Recomendación: no suspender el tratamiento opioide [50].

- Antiepilépticos: no hemos encontrado referencias aconsejando o desaconsejando su uso como tratamiento analgésico en la situación actual. Por lo tanto, no observamos, con la evidencia actual, ninguna contraindicación a su uso en las indicaciones aprobadas. Recomendación: seguir la práctica habitual.

- Anestésicos locales: monitorizar ECG (intervalo PR y QTc además de trastornos del ritmo]. Hay que recordar que aún no está caracterizada con precisión la cardiopatía post-COVID-19.

- Tratamientos tópicos aplicados en hospital de día: desinfección previa de la zona de aplicación con lavado seguido de solución hidroxialcóholica de clorhexidina. Recomendación: mantener las precauciones para contacto directo con el paciente y extremarlas en el caso de que la aplicación sea cercana a la vía aérea.

- Terapia intratecal, técnicas neuromoduladoras y neurodestructivas: seguir las recomendaciones de estratificación de riesgo ASIPP y las detalladas en los Anexos 4 y 5. Recomendación: dar preferencia a las técnicas de radiofrecuencia sobre las de administración de esteroides en indicaciones similares. En el caso de uso de corticoide, seguir las recomendaciones anteriores usando la menor dosis posible y usando de elección dexametasona o betametasona. Los pacientes en tratamiento con baclofeno y/o clonidina intratecal que precisen un recambio de bomba se considerarán urgentes y preferentes respectivamente. Los que estén en tratamiento opioide intratecal con imposibilidad de rotación a otra vía de una manera segura y que precisen un recambio de bomba, también se recomienda se consideren preferentes.

- Terapia con plasma rico en plaquetas: la AEMPS, en su última actualización (17 de enero de 2018) del "Documento de preguntas y respuestas en torno al uso terapéutico no sustitutivo de plasma autólogo y sus fracciones, componentes o derivados" (51), responde entre otras a las siguientes preguntas que nos guiarán para su uso en el contexto COVID-19:

- ¿Cuáles son las contraindicaciones del procedimiento? Al no tratarse de un producto de fabricación industrial, no existe una ficha técnica del producto. Es más, al tratarse de diferentes tipos de productos, esta información podrá depender del producto administrado. Es responsabilidad del facultativo prescriptor conocer qué producto está utilizando y ofrecer información al paciente de los posibles riesgos asociados al tratamiento.

- ¿Es obligatoria la realización de pruebas analíticas? Los productos derivados de la sangre tienen la potencialidad de transmitir diferentes enfermedades infecciosas. El médico prescriptor de un producto de estas características tiene que adoptar las medidas precisas de control, vigilancia y trazabilidad que impidan la transmisión de enfermedades infecciosas. El propio artículo 5 de la Directiva 2001/83/ $C E$, de 6 de noviembre, enmarca este tipo de usos de acuerdo con la prescripción de un facultativo reconocido, para un paciente individual y bajo su responsabilidad personal directa. Al tratarse de un uso autólogo, el riesgo de transmisión de enfermedad al propio sujeto depende esencialmente de la utilización de una técnica "limpia". Sin embargo, es necesario considerar que, además de asegurar la calidad y la trazabilidad del producto utilizado, el conocimiento del estado serológico de un paciente puede contribuir a garantizar la seguridad del personal que participa en la fabricación y, eventualmente, servir como defensa al propio facultativo responsable en el caso de seroconversión tras un procedimiento autólogo. Finalmente, podrá ser de interés en determinadas indicaciones conocer si el producto utilizado contiene ciertos virus a la hora de decidir la conveniencia o no de aplicar este tratamiento. Por todo ello, se debe tomar como norma de referencia las directrices genéricas ya desarrolladas para otras substancies de origen humano para uso clínico recogidas en el capítulo 29 de la 3. ${ }^{a}$ edición de la Guía del Consejo de Europa sobre Calidad y Seguridad de Tejidos y Células para aplicación humana.

Recomendación: la SED aconseja descartar, con todas las garantías disponibles, una infección activa por SARS-COV-2, antes de la aplicación de estas técnicas.

- Ozono:

- En el registro [52) se pueden consultar tres ensayos clínicos en marcha (uno reclutando) para el uso de ozono como posible tratamiento adyuvante del ozono en COVID-19.

- Un reciente estudio publicado en la REDAR aboga por su uso potencial en pacientes COVID-19 para el tratamiento de la enfermedad [53].

- La International Scientific Committee of Ozone Therapy ha publicado un documento sobre el uso potencial del Ozono en SARS-CoV-2/ COVID-19-ISC03/QAU/00/04 (54), pero no hace ninguna referencia específica a su uso y seguridad en técnicas analgésicas.

- No hemos encontrado referencias aconsejando o desaconsejando su uso como terapia analgésica primaria o alternativa en la situación actual.

Recomendación: no observamos, con la evidencia actual, ninguna contraindicación a su uso en las indicaciones aprobadas y siguiendo los protocolos sobre técnicas reflejados en este documento.

- Toxina botulínica: la toxina botulínica aumenta la respuesta inmune innata (55) y también se ha especulado sobre su uso para tratar síntomas asociados a COVID-19 [56]. 
Recomendación: no observamos, con la evidencia actual, ninguna contraindicación a su uso en las indicaciones aprobadas y siguiendo los protocolos sobre técnicas reflejados en este documento.

\section{Pacientes con inmunidad adquirida}

Los pacientes con inmunidad adquirida y sin tratamiento activo antivírico, en principio no tienen un riesgo sobreañadido y deberían tratarse sin limitaciones siempre que la enfermedad no le haya dejado insuficiencias residuales (respiratorias, hepáticas, renales, neurológicas y cardiológicas], por lo que se recomienda una evaluación completa antes de indicar cualquier nuevo tratamiento o modificar uno previo.

Tras recientes comunicaciones de un número bajo de reinfecciones, resta clarificar si se trata de falsos positivos en pruebas PCR (o falsos negativos previamente), así como si se trata de nuevas mutaciones del virus que tampoco conocemos; si fuera el caso, tendrían inmunidad parcial o total ante la nueva cepa. En cualquier caso, serán tratados como pacientes COVID + en función de estas pruebas serológicas.

Según comunica SEMES en su página web (www. semes.org), un paciente con remisión de síntomas y un test negativo de $\mathrm{ARN}$ vírico no quiere decir que esté libre al completo de carga viral. La OMS sugiere, por tanto, antes de confirmar la eliminación de la infección por SARS-COV-2, realizar test de detección del ARN vírico en muestras obtenidas, tanto del tracto respiratorio superior como del inferior (esputo).

\section{LAVADO DE MANOS}

El frecuente lavado de manos es una práctica básica recomendada por la OMS para el control de enfermedades infecciosas [57]. La forma correcta de hacerlo dura de 40 a 60 segundos y se detalla en la Figura 5.

\section{¿Cómo lavarse las manos?}

¡Lávese las manos solo cuando estén visiblemente sucias! Si no, utilice la solución alcohólica

(1) Duración de todo el procedimiento: 40-60 segundos

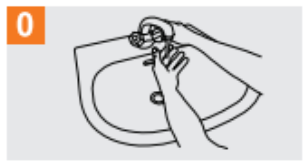

Mójese las manos con agua;

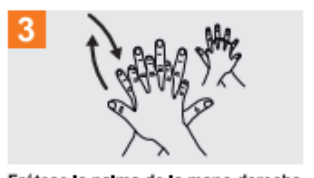

Frótese la palma de la mano derecha contra el dorso de la mano izquierda

6

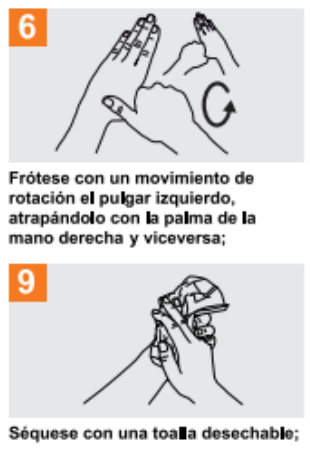

Séquese con una toalla desechable;
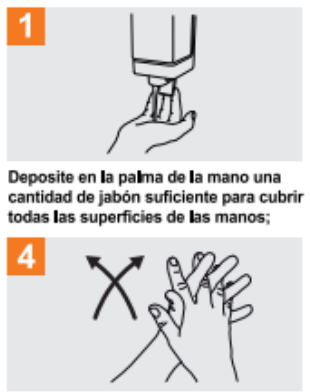

Frótese las palmas de las manos entre si, con los dedos

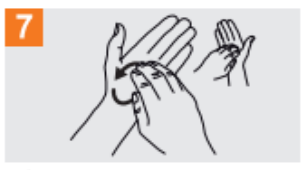

Frótese la punta de los dedos de la mano derecha contra la palma de

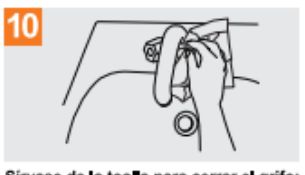

Sirvase de la toalla para cerrar el grifo;

Seguridad del Paciente

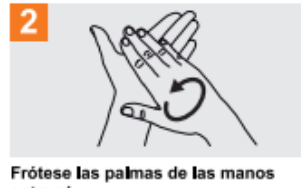

Frótese las palmas de las manos entre sis

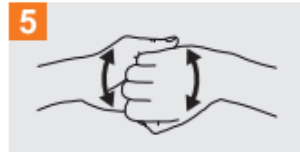

Frótese el dorso de los dedos de con la palma de la man。

8

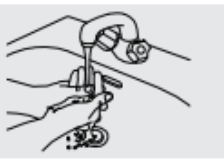

Enjuáguese las manos con agua;

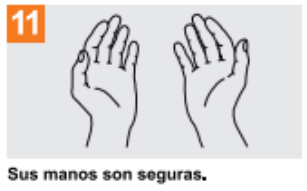

Sus manos son seguras.

\section{SAVE LIVES}

Fuente: Organización Mundial de la Salud. https://www.who.int/gpsc/information centre/gpsc_lavarse_manos_poster_es.pdf?ua=1

Fig. 5. ¿Cómo lavarse las manos? 


\section{EQUIPOS DE PROTECCIÓN PERSONAL (EPI)}

Los EPI son fundamentales para la protección del personal y de los pacientes. Los actos médico-quirúrgicos y de enfermería requieren, en muchas ocasiones, un contacto directo con el paciente, exponiéndonos y exponiendo al riesgo de contagio. En plena evolución de la pandemia, y la lentitud o falta de pruebas de detección, aún es pronto para clarificar qué porcentaje real de trabajadores sanitarios han sido infectados. En un primer estudio publicado recientemente, de un total de 6800 empleados del Hospital 12 de Octubre de Madrid, 2085 (30,6 \%) fueron analizados durante el periodo del 1 al 29 de marzo de 2020, algunos de ellos repetidamente (2286 muestras totales). Se confirmaron que un total de 791 trabajadores estaban infectados, lo que representa el $38 \%$ de los examinados y el 11,6\% de todos los trabajadores del hospital [58]. Esta cifra se compara negativamente con los resultados de la primera ronda de seroprevalencia publicada por el ministerio (59), que muestra una prevalencia estimada de anticuerpos IgG frente a SARS-Cov2 en España es de un 5,0 \% (95 \% IC: 4,7-5,4\%), aunque con una marcada variabilidad geográfica y mayor prevalencia en ciudades donde la proporción de positivos es mayor en residentes de grandes ciudades (> 100.000 habitantes) 6,4\% (IC $95 \%$ : 5,8-7,1].

En la Tabla III se muestran los 3 tipos de EPI aconsejados para diferentes entornos asistenciales: desde el equipo básico en tareas de limpieza, el medio en entornos de paciente quirúrgico no COVID +, hasta el avanzado en unidades de cuidados intensivos e intervenciones con paciente COVID +.

En los Anexos 1 a 3 se detallan las protecciones para cada contexto, incluido pacientes y personal administrativo.
Los vídeos demostrativos de la colocación y retirada de los EPI se pueden consultar en https://www. sedar.es/index.php/recomendaciones-coronavirus y https://enfermeriatv.es/es/coronavirus-protocoloepis/.

\section{TIPOS DE MASCARILLAS Y SU USO CORRECTO}

La OMS recomienda el uso de mascarillas como una medida de protección para no contraer ni contagiar la enfermedad [60], pero las mascarillas difieren mucho entre ellas y su colocación debe seguir unas normas.

La Figura 6 explica claramente los diferentes tipos de mascarillas. Obsérvese las importantes diferencias. En los Anexos 1 a 3 pueden consultar las recomendaciones de los tres tipos de mascarillas aconsejadas en los entornos asistenciales de las unidades de dolor. También se seguirán las normas del fabricante en cuanto al tiempo de uso de las mismas con eficacia demostrada.

En cuanto a su colocación, hay que seguir unas normas:

- Antes de ponerse una mascarilla, lávese las manos con un desinfectante a base de alcohol o con agua y jabón.

- Cúbrase la boca y la nariz con la mascarilla y asegúrese de que no haya espacios entre su cara y la máscara.

- Evite tocar la mascarilla mientras la usa. Si lo hace, lávese las manos con un desinfectante con capacidad viricida o con agua y jabón.

- Cámbiese de mascarilla tan pronto como esté húmeda y no reutilice las mascarillas de un solo uso.

TABLA III

EQUIPOS DE PROTECCIÓN PERSONAL

\begin{tabular}{|c|c|c|}
\hline $\begin{array}{c}\text { Equipo básico } \\
45 \text { GSM }\end{array}$ & $\begin{array}{c}\text { Equipo medio } \\
70 \text { GSM }\end{array}$ & $\begin{array}{c}\text { Equipo avanzado } \\
180 \text { GSM }\end{array}$ \\
\hline & & \\
\hline & &
\end{tabular}




\begin{tabular}{|c|c|c|c|c|c|}
\hline Equipo & $\underline{\text { Tipo }}$ & Foto & $\begin{array}{l}\text { Protección del personal } \\
\text { que la lleva contra } \\
\text { organismos infecciosos }\end{array}$ & $\begin{array}{l}\frac{\text { Barrera para no contagiar / }}{\text { evita la emisión de organismos }} \\
\text { infecciosos al ambiente }\end{array}$ & Observaciones \\
\hline \multirow{2}{*}{$\begin{array}{l}\text { Mascarillas auto filtrantes } \\
\text { desechables (Reutilizables } \\
\text { solo las marcadas con "R" } \\
\text { (solo algunos modelos de } \\
\text { FPP2 y FPP3). Modelos "NR" } \\
\text { (no reutilizable) de uso para } \\
\text { un solo turno. }\end{array}$} & $\begin{array}{l}\text { FFP1 sin válvula } \\
\text { de exhalación }\end{array}$ & & & & $\begin{array}{l}\text { Es un equipo de protección pero su } \\
\text { eficacia de filtración minima (78\%) no } \\
\text { garantiza protección suficiente frente a } \\
\text { organismos infecciosos. Limita la } \\
\text { propagación del contagio. }\end{array}$ \\
\hline & $\begin{array}{l}\text { FFP2 } \sin \text { válvula } \\
\text { de exhalación }\end{array}$ & & & & $\begin{array}{l}\text { Protege y limita la propagación del } \\
\text { contagio. }\end{array}$ \\
\hline \multirow{2}{*}{$\begin{array}{l}\text { Diseñadas para trabajar de } \\
\text { fuera hacia dentro } \\
\text { Norma EN } 149\end{array}$} & $\begin{array}{l}\text { FFP3 con válvula } \\
\text { de exhalación }\end{array}$ & & & & $\begin{array}{l}\text { Todas las mascarillas auto filtrantes } \\
\text { FPP3 disponen de válvula de exhalación. } \\
\text { Protege pero no limita la propagación } \\
\text { del contagio. }\end{array}$ \\
\hline & $\begin{array}{l}\text { FFP2 con válvula } \\
\text { de exhalación }\end{array}$ & & & & $\begin{array}{l}\text { Protege pero no limita la propagación } \\
\text { del contagio. }\end{array}$ \\
\hline $\begin{array}{l}\text { Mascarilla quirúrgica NO EPI } \\
\text { desechable } \\
\text { Norma EN 14683. Trabaja de } \\
\text { dentro a fuera. }\end{array}$ & I, II, y $\| R$ & & & & $\begin{array}{l}\text { No es un equipo de protección. No } \\
\text { protege pero limita la propagación del } \\
\text { contagio. El tipo I sólo debe ser utilizado } \\
\text { por pacientes, no por personal médico. }\end{array}$ \\
\hline $\begin{array}{l}\text { Mascarillas higiénicas NO EPI } \\
\text { desechable (mascarilla sin } \\
\text { marcado CE, no conforme a } \\
\text { norma). Trabaja de dentro a } \\
\text { fuera. }\end{array}$ & N.A. & & & & $\begin{array}{l}\text { No es un equipo de protección. No } \\
\text { protege pero podria limitar la } \\
\text { propagación del contagio. No sujeto a } \\
\text { norma, eficacia no testada. }\end{array}$ \\
\hline $\begin{array}{l}\text { Semimáscara buconasal con } \\
\text { filtros (diseñadas para } \\
\text { trabajar de fuera hacia } \\
\text { dentro) } \\
\text { EN } 140\end{array}$ & $\begin{array}{l}\text { Diferentes } \\
\text { modelos }\end{array}$ & & & & $\begin{array}{l}\text { Todas disponen de válvula de } \\
\text { exhalación. Protege pero no limita la } \\
\text { propagación del contagio. Reutilizable }\end{array}$ \\
\hline
\end{tabular}

Fuente: cita bibliográfica [61].

Fig. 6. Tipos de mascarillas y grado de protección que ofrecen.

- Para quitarse la mascarilla: hágalo por detrás (no toque la parte delantera de la mascarilla), deséchela inmediatamente en un recipiente cerrado y lávese las manos con un desinfectante con capacidad virucida o con agua y jabón. En la web hay vídeos donde consultar la correcta colocación y retirada de las mascarillas [62].

\section{GAFAS Y PROTECTORES FACIALES (PANTALLAS)}

Se deben usar gafas o protectores faciales para prevenir la exposición de la mucosa ocular al virus. Las gafas deben ajustarse a las características faciales del usuario y deben ser compatibles con la mascarilla, tal como recomienda el Centro Europeo de Prevención y Control de Enfermedades [63).

Cualquiera de las dos opciones, gafas estancas o pantallas de amplia superficie, han mostrado su utilidad para prevenir el contagio. La protección ocular (vía conjuntiva) que ofrecen las gafas estancas parece superior a las pantallas, y la cutánea facial mayor en las pantallas de $180^{\circ}$ de circunferencia mínima.

La mascarilla facial sigue siendo obligatoria en ambas opciones, que son recomendables a distancias menos de 2 metros y obligatorias en casos de manejo de la vía aérea y aerosoles.
El procedimiento para la desinfección de las pantallas protectoras se puede encontrar en varias páginas de internet [64].

\section{DESINFECCIÓN DE ESPACIOS Y GESTIÓN DE RESIDUOS}

Todos los centros deberán tener protocolos de limpieza, desinfección y gestión de residuos, de acuerdo con los departamentos de salud laboral (o empresas contratadas) y seguir las recomendaciones oficiales y utilización de virucidas adecuados [65].

Los residuos generados en la atención del paciente COVID + se consideran residuos de Clase III y, por lo tanto, deberán ser eliminados como residuos biosanitarios especiales. El contenedor de residuos, una vez lleno, se cerrará y antes de su retirada se desinfectará en su superficie con un paño desechable impregnado en desinfectante.

Por su simplicidad e infografía, recomendamos el protocolo del Servicio de Salud del Principado de Asturias (Figura 7).

(https: / / www. astursalud.es/documents/31867/946211/Coronavirus++Eliminaci\%C 3\%B3n+de+residuos+limpieza+y+desinfecci\%C3\%B3n. pdf/a2d7bfe2-9bff-3957-d4a7-d47f4db96b01) 


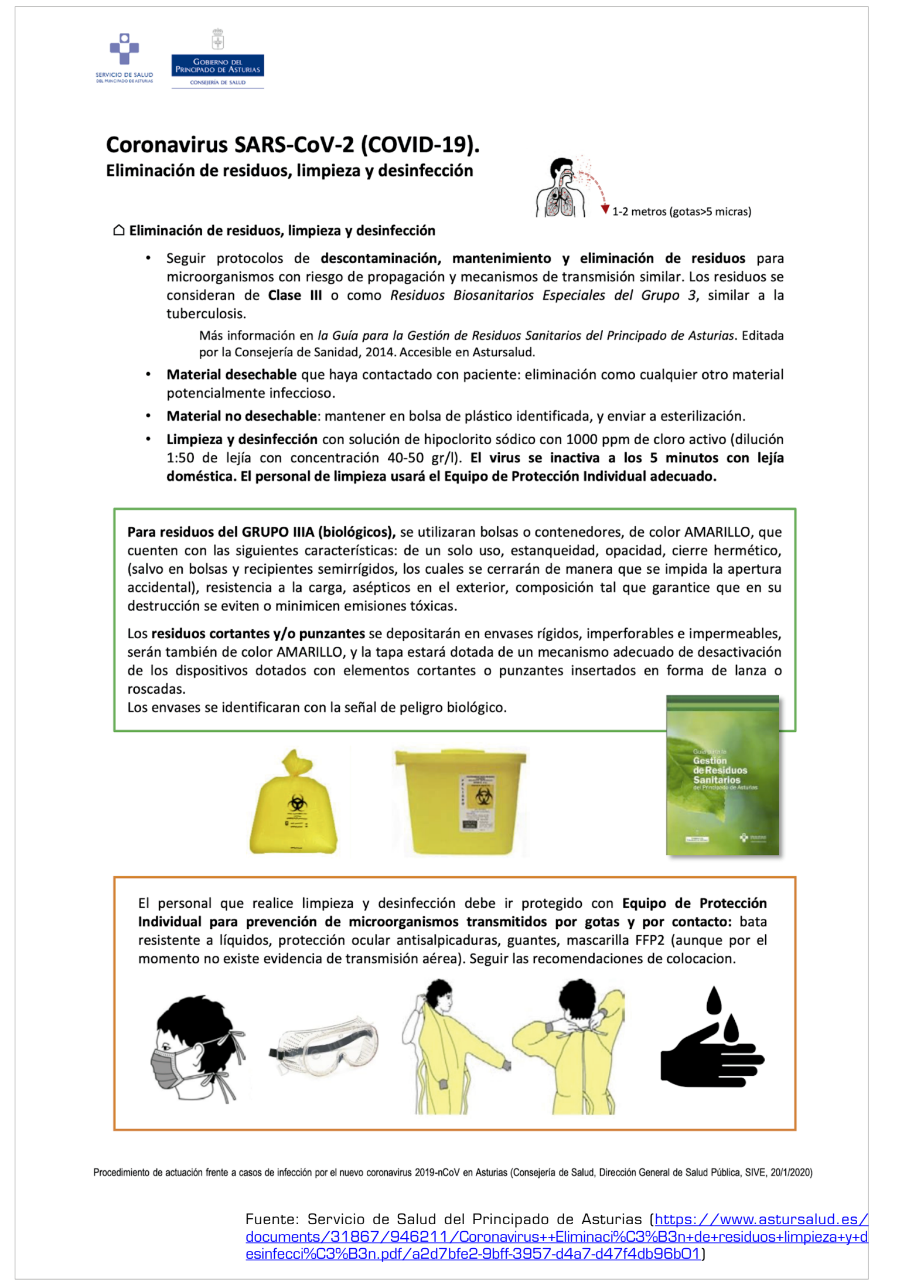

Fig. 7. Coronavirus Sars-Cov-2 (COVID-19). Eliminación de residuos, limpieza y desinfección. 


\section{ANEXOS}

ANEXO 1

RECOMENDACIONES DE PROTECCIÓN EN SALA DE ESPERA Y ESPACIOS NO ASISTENCIALES COMUNES

\begin{tabular}{|c|c|c|c|c|c|}
\hline & $\begin{array}{l}\text { Personal } \\
\text { sanitario }\end{array}$ & $\begin{array}{c}\text { Personal } \\
\text { administrativo }\end{array}$ & $\begin{array}{l}\text { Paciente } \\
\text { exCOVID* }\end{array}$ & $\begin{array}{c}\text { Paciente } \\
\text { COVID }(-)^{* *}\end{array}$ & $\begin{array}{c}\text { Paciente } \\
\text { COVID }[+] * \star *\end{array}$ \\
\hline Distancia de seguridad & \multicolumn{4}{|c|}{2 metros } & $N / A$ \\
\hline Mascarilla & FFP2 & FFP2 & Quirúrgica & Quirúrgica & $N / A$ \\
\hline Lavado / Desinfección de manos & Sí & Sí & Sí & Sí & $N / A$ \\
\hline Gorros & No & No & No & No & $N / A$ \\
\hline Pantallas & No & No & No & No & $N / A$ \\
\hline Batas impermeables & No & No & No & No & $N / A$ \\
\hline Polainas & Sí & Sí & No & No & $N / A$ \\
\hline
\end{tabular}

*Paciente exCOVID: paciente más de 21 días asintomático y/o con dos PCR negativas, separadas 3 días en los 10 días previos a la visita. El paciente puede ser portador cutáneo por reciente contacto.

* Paciente COVID (-): paciente sin síntomas de enfermedad por COVID-19 (score) en los últimos 30 días y sin haber tenido contacto con paciente COVID (+) en los últimos 30 días. No se puede excluir con total certeza (ni con PCR reciente) que sea portador asintomático.

$\star \star \star$ Paciente COVID $[+$ ): N/A dado que estos pacientes deben ser tratados en un entorno fuera de consultas.

Los acompañantes deben seguir las mismas normas que los pacientes.

El lavado de manos y/o el uso de gel desinfectante debe ser obligatorio antes de la colocación de guantes a la entrada de la sala de espera.

El uso de los lavabos comunes se hará con las mismas normas de higiene de lavado de manos meticulosa antes y después de su uso, solicitando al finalizar que se higienice el baño por personal de limpieza.

La limpieza y desinfección con viricidas de los muebles (ej: asientos, mesas...) y material informático se hará con una frecuencia que dependerá de su uso, pero un mínimo de dos veces por turno. 


\section{ANEXO 2}

RECOMENDACIONES DE PROTECCIÓN EN CONSULTA MÉDICA CON/SIN CONTACTO FÍSICO CON EL PACIENTE Y/O REVISIÓN MANUAL DE PRUEBAS QUE APORTE. PLANTA DE HOSPITALIZACIÓN EN PACIENTE COVID [+]

\begin{tabular}{|c|c|c|c|c|c|}
\hline & $\begin{array}{l}\text { Personal } \\
\text { sanitario }\end{array}$ & $\begin{array}{c}\text { Personal } \\
\text { administrativo }\end{array}$ & $\begin{array}{l}\text { Paciente } \\
\text { exCOVID* }\end{array}$ & $\begin{array}{l}\text { Paciente } \\
\text { COVID }(-)^{* *}\end{array}$ & $\begin{array}{l}\text { Paciente COVID }[+]^{* \star *} \\
\text { planta hospitalización }\end{array}$ \\
\hline $\begin{array}{l}\text { Distancia de } \\
\text { seguridad }\end{array}$ & \multicolumn{5}{|c|}{$\begin{array}{l}\text { Minimizar la distancia y tiempo de exposición } \\
\text { Limitar el número de personas en la consulta }\end{array}$} \\
\hline Mascarilla & FFP2 & FFP2 & Quirúrgica & Quirúrgica & $\begin{array}{l}\text { FFP1 siempre que sea } \\
\text { posible (ausencia de } \\
\text { clínica respiratoria sig) }\end{array}$ \\
\hline Guantes & Sí & Sí & Sí & Sí & Sí \\
\hline Gorros & Sí & Sí & No & No & No \\
\hline Pantallas & Sí & Sí & No & No & No \\
\hline Batas impermeables & Sí (en contacto) & No & No & No & No \\
\hline Polainas & SI & SI & $\mathrm{SI}$ & SI & NO \\
\hline
\end{tabular}

*Paciente exCOVID: paciente más de 21 días asintomático y/o con dos PCR negativas separadas 3 días en los 10 días previos a la visita. El paciente puede ser portador cutáneo por reciente contacto.

* Paciente COVID (-): paciente sin síntomas de enfermedad por COVID-19 (score) en los últimos 30 días y sin haber tenido contacto con paciente COVID (+) en los últimos 30 días. No se puede excluir con total certeza (ni con PCR reciente) que sea portador asintomático.

***Paciente COVID $[+]$ : se refiere solo a urgencias que no se puedan solucionar sin asistencia presencial. El uso de equipo EPI completo sin superficies de exposición cutánea para el personal en contacto con el paciente es obligatorio.

Además de PCR, realizar test de anticuerpos lgM + IgG siempre que se pueda para catalogar con mayor precisión al paciente y personal.

Los acompañantes deben seguir las mismas normas que los pacientes.

Si el paciente aporta pruebas que se deban revisar, hacerlo con guantes y limpiar las zonas en contacto con el material al finalizar la consulta.

La limpieza y desinfección con virucidas homologados de los muebles (ej: asientos, mesas, etc.), y material informático se hará con una frecuencia que dependerá de su uso, pero un mínimo de dos veces por turno. 
ANEXO 3

RECOMENDACIONES DE PROTECCIÓN PARA TÉCNICAS ANALGÉSICAS EN HOSPITAL DE DÍA (\#), SALAS DE TÉCNICAS, RADIOLOGÍA INTERVENCIONISTA, QUIRÓFANO Y SALAS DE RECUPERACIÓN

\begin{tabular}{|l|c|c|c|c|}
\cline { 2 - 5 } \multicolumn{1}{c|}{} & \multicolumn{1}{c|}{ Personal sanitario } & $\begin{array}{c}\text { Paciente } \\
\text { exCOVID }\end{array}$ & $\begin{array}{c}\text { Paciente } \\
\text { COVID }[-]^{* *}\end{array}$ & $\begin{array}{c}\text { Paciente } \\
\text { COVID }[+]^{* * *}\end{array}$ \\
\hline Distancia de seguridad & \multicolumn{2}{|c|}{$\begin{array}{c}\text { Minimizar la distancia y tiempo de exposición } \\
\text { Limitar el número de personas en la sala }\end{array}$} \\
\hline Mascarilla & $\begin{array}{c}\text { FFP2 (FFP3 si se va a } \\
\text { manipular la vía aérea o se } \\
\text { van a precisar aerosoles] }\end{array}$ & Quirúrgica & Quirúrgica & $\begin{array}{c}\text { FFP2 sin } \\
\text { válvula }\end{array}$ \\
\hline Guantes & Si (doble) & Sí & Sí & Sí \\
\hline Gorros & Sí & No & No & Sí \\
\hline Pantallas & Sí & No & No & Sí \\
\hline Batas impermeables & Sí & No & No & Sí \\
\hline Polainas & Sí & Sí & Sí & Sí \\
\hline
\end{tabular}

*Paciente exCOVID: paciente más de 21 días asintomático y/o con dos PCR negativas separadas 3 días en los 10 días previos a la visita. El paciente puede ser portador cutáneo por reciente contacto.

* *aciente COVID (-): paciente sin síntomas de enfermedad por COVID-19 (score) en los últimos 30 dias y sin haber tenido contacto con paciente COVID [+] en los últimos 30 días. No se puede excluir con total certeza (ni con PCR reciente) que sea portador asintomático.

$\star \star \star$ Paciente COVID (+): se refiere solo a urgencias en paciente sin clínica respiratoria significativa. El uso de equipo EPI completo sin superficies de exposición cutánea para el personal en contacto con el paciente, es obligatorio. El circuito de entrada, estancia y salida del paciente debe asegurar la ausencia de exposición a otros pacientes y personal no sanitario. El recovery se hará en el quirófano. El paciente debe ser intervenido el último de la mañana e idealmente en un quirófano preparado para COVID.

Utilizar siempre que se pueda material de un solo uso. Si el material deberá ser re-esterilizado, tener un circuito preparado para miniminzar contaminación.

La limpieza y desinfección con viricidas se debe hacer entre pacientes, sin poder recomendar en estos momentos el tiempo mínimo de reposo entre pacientes.

El desecho de materiales, seguirá la normativa del ministerio [8].

\# En pacientes de riesgo que acudan a rellenos de bombas intratecales, se tratarán con el mismo nivel de protección que un paciente COVID +. 
ANEXO 4

PROTOCOLO DE TEST PREOPERATORIOS EN FUNCIÓN DE LA PRESTACIÓN

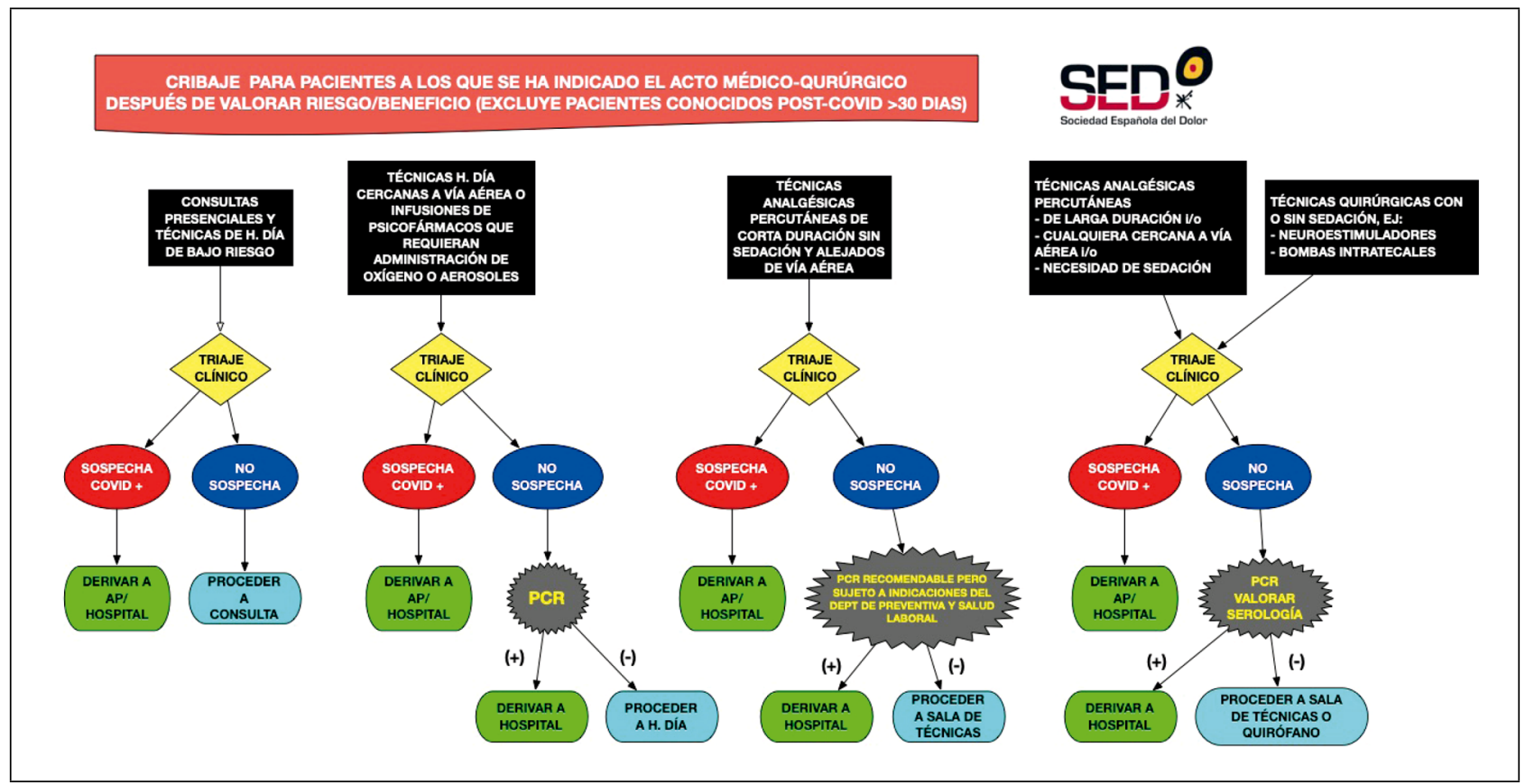

Disponible en: https://www. sedolor.es/download/cribaje-para-pacientes-a-los-que-se-ha-indicado-el-acto-medico-qururgicodespues-de-valorar-riesgo-beneficio-excluye-pacientes-conocidos-post-covid-30-dias/

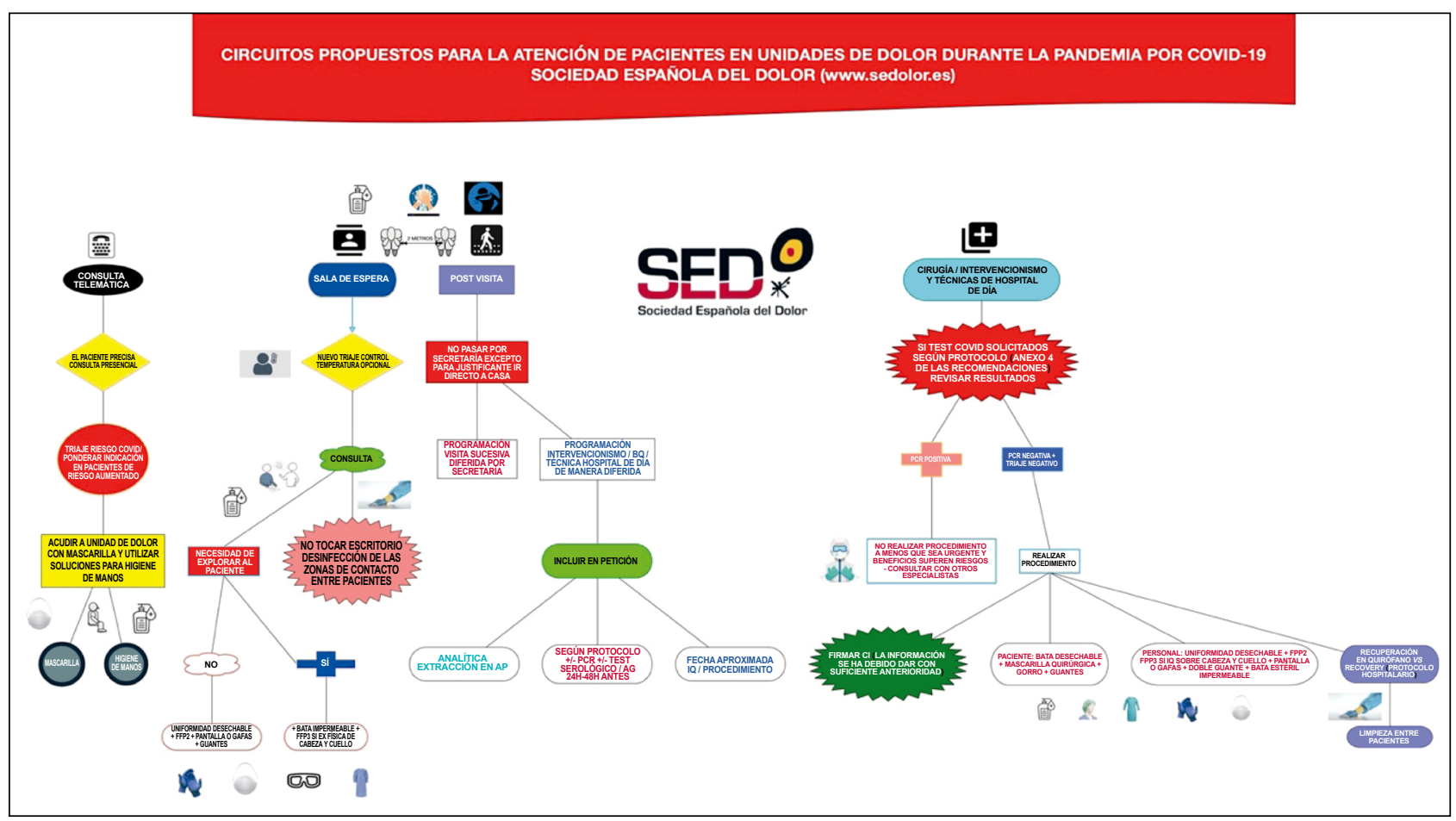

Disponible en: https://www.sedolor.es/download/circuitos-propuestos-para-la-atencion-de-pacientes-en-unidades-de-dolordurante-la-pandemia-por-covid-19/ 


\title{
ANEXO 6
}

DOCUMENTO DE ACOMPAÑAMIENTO AL CONSENTIMIENTO INFORMADO PARA TÉCNICAS ANALGÉSICAS INVASIVAS E INTERVENCIONES QUIRÚRGICAS CON FINALIDADES ANALGÉSICAS

\author{
DOCUMENTO INFORMATIVO DE ACOMPAÑAMIENTO AL CONSENTIMIENTO \\ INFORMADO PARA INTERVENCIÓN QUIRÚRGICA O TÉCNICA INTERVENCIONISTA CON \\ FINALIDAD ANALGÉSICA EN EL CONTEXIO DE LA PANDEMIA POR COVID-19
}

El propósito de este documento informativo es completar el consentimiento informado específico sobre la técnica analgésica o intervención quirúrgica propuesto para tratar su dolor, teniendo en cuenta los condicionantes ocasionados por la pandemia por COVID-19.

Su equipo sanitario, responsable del tratamiento de su dolor, le ha propuesto llevar a cabo dicha intervención ya habiendo sopesado los beneficios y riesgos potenciales en el contexto excepcional de la pandemia, siempre basándose en la mejor evidencia científica disponible.

Se pueden dar los siguientes escenarios:

- Que usted padezca una infección activa por COVID-19. En este caso, es muy recomendable posponer el procedimiento a menos que se trate de una urgencia, para lo que será puntual e individualmente informado.

- Que usted haya pasado la enfermedad COVID-19. En este caso, con pruebas confirmatorias de haber pasado la infección y valorando clínicamente que no le haya dejado secuelas que puedan modificar el tratamiento propuesto, su equipo le recomendará hacerse el procedimiento o modificaciones de este, para lo cual deberá dar su consentimiento tras haber sido informado y se le hayan aclarado las dudas personalizadas que le puedan surgir.

- Que usted no haya pasado o desconozca si ha pasado la enfermedad COVID-19. En estos casos, se le propondrá seguir las recomendaciones protocolizadas por su centro de salud, que estarán basadas en las que dicta la autoridad competente y las recomendaciones de la Sociedad Española del Dolor. Estas recomendaciones, dependiendo de la fase en que nos encontremos, además de unas preguntas sobre síntomas y signos de la enfermedad por COVID-19, pueden incluir la necesidad de realizar una prueba de detección del virus, sus antígenos y/o los anticuerpos que se generan.

Su centro de salud habrá tomado todas las precauciones de asepsia necesarias y diseñado un circuito específico para pacientes como usted que reducirán el riesgo de infección tanto como sea posible.

Todo esto se hace para que tanto usted, sus acompañantes como el personal que le atiende tengamos un entorno lo más seguro posible y se le pueda realizar el procedimiento con las mayores garantías de éxito

Disponible en: https://www.sedolor.es/download/documento-informativo-de-acompan\%cc\%83amiento-alconsentimiento-informado-para-intervencion-quirurgica-o-tecnica-intervencionista-con/ 


\section{BIBLIOGRAFÍA}

1. PROMIR España. Actualización en el "Estado del arte" del COVID-19 e impacto en el MIR [Video File]. 8 de mayo de 2020. [consultado el 27 de mayo 2020] [2:01:31]. Disponible en: https://www.youtube.com/watch?v=R6c D-qlbLU

2. Centro de Coordinación de Alertas y Emergencias Sanitarias. Enfermedad por coronavirus, COVID-19 [Internet]. Última actualización el 18 de mayo de 2020. Ministerio de Sanidad. [consultado el 27 de mayo 2020]. Disponible en: https:// www.mscbs.gob.es/profesionales/saludPublica/ccayes/ alertasActual/nCov-China/documentos/ITCoronavirus.pdf

3. European Centre for Disease Prevention and Control. COVID-19 situation update for the EU/EEA and the UK, as of 26 May 2020 [Internet]. Última actualización el 26 de mayo de 2020. European Centro for Disease Prevention and Control. [consultado el 27 de mayo 2020]. Disponible en: https://www.ecdc.europa.eu/en/cases-2019-ncov-eueea

4. Asociación Española de Cirujanos, Sociedad Española de Anestesiología y Reanimación, Sociedad Española de Medicina Preventiva, Salud Pública e Higiene, Sociedad Española de Enfermedades Infecciosas y Microbiología Clínica, Asociación Española de Enfermería Quirúrgica. Recomendaciones para la programación de cirugía en condiciones de seguridad durante el periodo de transición de la pandemia COVID-19 [Internet]. 16 de mayo de 2020. Ministerio de Sanidad. [consultado el 27 de mayo 2020]. Disponible en: https://www. mscbs.gob.es/en/profesionales/saludPublica/ccayes/alertasActual/nCov-China/documentos/200517-DOCUMENTO_ CIRUGIA-FINAL_(2).pdf

5. Eur-Lex. Hoja de ruta común europea para el levantamiento de las medidas de contención de la COVID-19 2020/C 126/01 C/2020/2419 [Internet]. 17 de abril de 2020. Unión Europea. [consultado el 27 de mayo 2020]. Disponible en: https://eur-lex.europa.eu/legal-content/ES/ TXT/?uri=CELEX:52020XC0417(06)

6. Kissler SM, Tedijanto C, Goldstein E, Grad YH, Lipsitch M. Projecting the transmission dynamics of SARS-CoV-2 through the postpandemic period. Science. 202022;368(6493):8608. DOI: 10.1126/science.abb5793.

7. European Centre for Disease Prevention and Control. Infection prevention and control and preparedness for COVID-19 in healthcare settings [Internet]. ECDC Technical Report. 31 de marzo de 2020. [consultado el 27 de mayo 2020]. Disponible en: https://www.ecdc.europa.eu/sites/default/ files/documents/Infection-prevention-control-for-the-careof-patients-with-2019-nCoV-healthcare-settings_update31-March-2020.pdf

8. Sociedad Española de Medicina Preventiva, Sociedad Española de Salud y Seguridad en el Trabajo, Consejo General de Colegios Oficiales de Médicos, Consejo General de Enfermería. Prevención y control de la infección en el manejo de pacientes con COVID-19 [Internet]. Gobierno de España. 20 de mayo de 2020 [consultado el 27 de mayo 2020]. Disponible en: https://www.mscbs.gob.es/profesionales/ saludPublica/ccayes/alertasActual/nCov-China/documentos/Documento_Control_Infeccion.pdf

9. Ministerio de Sanidad. Recomendaciones del uso de mascarillas en la comunidad en el contexto de COVID-19 [Internet]. Gobierno de España. 20 de abril de 2020 [consultado el 27 de mayo 2020]. Disponible en: http://www.saludlaboral. ugtcyl.es/wp-content/uploads/2020/04/Recomendaciones_uso_mascarillas_ambito_comunitario.pdf
10. Asociación Española de Pediatría/Sociedad Española de Infectología Pediátrica, Sociedad Española de Cuidados Intensivos Pediátricos, Sociedad Española de Medicina de Urgencias y Emergencias, Sociedad Española de Medicina Interna, Sociedad Española de Enfermedades Infecciosas y Microbiología Clínica, Sociedad Española de Medicina Tropical y Salud Internacional, Sociedad Española de Neumología y Cirugía Torácica, Sociedad Española de Medicina Intensiva. Crítica y Unidades Coronarias, Sociedad Española de Medicina Preventiva. Salud Pública e Higiene, Sociedad Española de Anestesiología, Reanimación y Terapéutica del Dolor, Sociedad Española de Farmacología Clínica, Sociedad Española de Farmacia Hospitalaria, Sociedad Española de Inmunología, Agencia Española de Medicamentos y Productos Sanitarios, Dirección General de Cartera Básica de Servicios del SNS y Farmacia, Consejo General de Colegios Oficiales de Médicos, Consejo General de Enfermería, Asociación de Especialistas en Enfermería del Trabajo, Asociación Española de Enfermería de Prevención y Control de Infecciones, Sociedad Española de Neumología y Cirugía Torácica. Manejo clínico del COVID-19: atención hospitalaria [Internet]. Gobierno de España. 20 de mayo de 2020 [consultado el 27 de mayo 2020]. Disponible en: https://www.mscbs.gob.es/profesionales/saludPublica/ccayes/alertasActual/nCov-China/ documentos/Protocolo manejo clinico ah COVID-19.pdf

11. European Pain Federation. EFIC COVID-19 Task Force [Internet]. EFIC. Última actualización el 22 de mayor de 2020 [consultado el 27 de mayo de 2020]. Disponible en: https:// europeanpainfederation.eu/efic-pain-research/covid-19/

12. Shanthanna H, Strand NH, Provenzano DA, Lobo CA, Eldabe S, Bhatia A, et al. Caring for patients with pain during the COVID-19 pandemic: consensus recommendations from an international expert panel. Anaesthesia. 2020. DOl: 10.1111/anae.15076.

13. Ley Orgánica 3/2018, de 5 de diciembre, de Protección de Datos Personales y garantía de los derechos digitales. BOE 294, de 6 de diciembre de 2018. Disponible en: https:// www.boe.es/buscar/pdf/2018/BOE-A-2018-16673-consolidado.pdf

14. Ley $41 / 2002$, de 14 de diciembre, básica reguladora de la autonomía del paciente y de los derechos y obligaciones en material de información y documentación clínica. BOE 274 de 15 de noviembre de 2002. Disponible en: https://www.boe. es/boe/dias/2002/11/15/pdfs/A40126-40132.pdf

15. Flórez García MT, García Pérez F, Aboitiz Cantalapiedra J, Pérez Manzanero MA, Echávarri Pérez C. Programas de ejercicios [Internet]. [consultado el 27 de mayo de 2020]. Disponible en: http://www.sermef-ejercicios.org/

16. Me rehabilito en casa [Internet]. 2020. [consultado el 27 de mayo de 2020]. Disponible en: https://www.merehabilitoencasa.es/

17. Hilty DM, Ferrer DC, Parish MB, Johnston B, Callahan EJ, Yellowlees PM. The Effectiveness of Telemental Health: A 2013 Review. Telemed E-health. 2013;19(6):444-54.

18. Eccleston C, Fisher E, Craig L, Duggan GB, Rosser BA, Keogh E. Psychological therapies (Internet-delivered) for the management of chronic pain in adults (Review). Cochrane Db Syst Rev. 2014;2014(2):CD010152. DOI: 10.1002/14651858.cd010152.pub2.

19. Tang WX, Zhang LF, Ai YQ, Li ZS. Efficacy of Internetdelivered cognitive-behavioral therapy for the management of chronic pain in children and adolescents. Medicine (Baltimore). 2018;97(36):e12061. DOI: 10.1097/ MD.0000000000012061. 
20. Ministerio de Sanidad. Documentos técnicos para profesionales [Internet]. Actualización diaria. [consultado el 27 de mayo de 2020]. Disponible en: https://www.mscbs.gob. es/en/profesionales/saludPublica/ccayes/alertasActual/ nCov-China/documentos.htm

21. Rahmé RJ. Twitter (mayo). [consultado el 27 de mayo de 2020]. Disponible en: https://twitter.com/RamyRahme/

22. European Centre for Disease Prevention and Control. Rapid Risk Assessment: Coronavirus disease 2019 (COVID-19) in the EU/EEA and the UK- ninth update [Internet]. 23 de abril de 2020 [consultado el 27 de mayor de 20२0]. Disponible en: https://www.ecdc.europa.eu/en/publications-data/ rapid-risk-assessment-coronavirus-disease-2019-covid19-pandemic-ninth-update

23. Sethuraman N, Jeremiah SS, Ryo A. Interpreting Diagnostic Tests for SARS-CoV-2. JAMA. 2020. DOI: 10.1001/ jama.2020.8259.

24. Wang W, Xu Y, Gao R, Lu R, Han K, Wu G, et al. Detection of SARS-CoV-2 in Different Types of Clinical Specimens. JAMA. 2020;323(18):1843-4. DOl: 10.1001/jama.2020.3786.

25. FIND. COVID-19 Diagnostic Resource Center [Internet]. 26 de mayo de 2020 [consultado el 27 de mayo de 2020]. Disponible en: https://finddx. shinyapps.io/COVID19DxData/

26. Zhao J, Yuan Q, Wang H, Liu W, Liao X, Su Y, et al. Antibody responses to SARS-CoV-2 in patients of novel coronavirus disease 2019. Clin Infect Dis. 2020; ciaa344. DOI: 10.1093/cid/ciaa344. doi:10.1093/cid/ciaa344.

27. Ministerio de Sanidad. Interpretación de las pruebas diagnósticas frente a SARS-CoV-2 [Internet]. Ministerio de Salud, Consumo y Bienestar Social. 24 de abril de 2020. [consultado el 27 de mayo de 2020). Disponible en: https:// www.mscbs.gob.es/profesionales/saludPublica/ccayes/ alertasActual/nCov-China/documentos/INTERPRETACION DE_LAS_PRUEBAS.pdf

28. World Health Organization. Laboratory testing for 2019 novel coronavirus (2019-nCoV) in suspected human cases [Internet]. 19 de marzo de 2020 [consultado el 27 de mayo de 2020]. Disponible en: https://www.who.int/publicationsdetail/laboratory-testing-for-2019-novel-coronavirus-in-suspected-human-cases-20200117

29. Sociedad Española del Dolor. Check list COVID-19/Sociedad Española del Dolor [Internet]. 13 de mayo de 2020 [consultado el 27 de mayor de 2020]. Disponible en: https: / / www. sedolor.es/download/check-list-covid-19-sociedad-espanoladel-dolor/

30. American Society of Interventional Pain Physycians. Checklist and risk stratification for opening of interventional pain management practices [Internet]. 2020 [consultado el 27 de mayo de 2020]. Disponible en: https://www.asipp.org/ asipp-updates/checklist-and-risk-stratification-for-opening-ofinterventional-pain-management-practices

31. Sociedad Española del Dolor. Adaptación SED al español de la Estratificación de riesgo ASIPP para pacientes candidatos a procedimientos de dolor intervencionista [Internet]. $13 \mathrm{de}$ mayo de 2020 [consultado el 27 de mayo de 2020]. Disponible en: https://www. sedolor.es/download/adaptacion-alespanol-de-la-estratificacion-de-riesgo-asipp-para-pacientescandidatos-a-procedimientos-de-dolor-intervencionista/

32. Sánchez Sempere AM, Núñez Palomo A, Castello Jurado M, Lomeña Villalobos JA, Sánchez Amezua Jl, Torres Maese $\mathrm{M}$, et al. Herramienta de apoyo al diagnóstico de COVID-19 [Internet]. 2020 [consultado el 27 de mayo de 2020]. Disponible en: https://triagecovid19.com/index.php

33. Col-legi de Metges de Barcelona. Plataforma para compartir copias de recetas privadas en papel: cómo enviar fotos de las recetas en papel de la asistencia médica privada [Internet]. 7 de abril de 2020 [consultado el 27 de mayo de 2020]. Disponible en: https://www.comb.cat/cast/actualitat/ noticies/noticies fitxa.aspx?Id=IZQgZ\%2ff3f\%2fdFIACcpAM Bug\%3d\%3d

34. REMPe. Receta médica privada electrónica [Internet]. 2019 [Consultado el 27 de mayo de 2020]. Disponible en: https://resources.rempe.es/landing/\#/inicio

35. Confederación Española de Familias de personas sordas. Cómo hablar con una persona sorda [Internet]. 2020 [Consultado el 27 de mayo de 2020]. Disponible en: https:// www. saludcastillayleon.es/es/covid-19/informacion-profesionales/recomendaciones-profesionales.ficheros/1571420Infograf\%C3\%ADa\%20C\%C3\%B3mo\%2Ohablar\%2Ocon\%20 una\%2Opersona\%20con\%2Osordera\%20-\%2OFIAPAS.pdf

36. Sociedad Española de Anestesiología, Reanimación y Terapéutica del Dolor. Recomendación para el manejo intraoperatorio de pacientes con sospecha o confirmación de infección por coronavirus COVID-19 [Internet]. [Consultado el 27 de mayo de 2020]. Disponible en: https://www.sedar.es/ images/site/Intraoperatorio y coronavirus.docx 003 1.pdf

37. European Centre for Disease Prevention and Control. Infection prevention and control and preparedness for COVID-19 in healthcare settings - third update [Internet]. ECDC Technical Report. 13 de mayo de 2020. [consultado el 27 de mayo 2020]. Disponible en: https://www.ecdc.europa.eu/ en/publications-data/infection-prevention-and-control-andpreparedness-covid-19-healthcare-settings

38. Instituto Nacional De Seguridad y Salud en el Trabajo, Centro Nacional de Medios de Protección, Inspección de Trabajo y Seguridad Social, Sociedad Española de Medicina y Seguridad en el Trabajo, Asociación Española de Especialistas en Medicina del Trabajo, Asociación Nacional de Medicina del Trabajo en el Ámbito Sanitario, Sociedad Española de Salud Laboral en la Administración Pública, Federación Española de Enfermería del Trabajo, Asociación de Especialistas en Enfermería del Trabajo. Procedimiento de actuación para los servicios de prevención de riesgos laborales frente la exposición al SARS-CoV-2 [Internet]. Ministerio de Sanidad. 22 de mayo de 2020 [Consultado el 27 de mayo de 2020]. Disponible en: https://www.mscbs.gob.es/en/profesionales/saludPublica/ccayes/alertasActual/nCov-China/documentos/PrevencionRRLL_COVID-19.pdf

39. Sacyl. Recomendaciones equipos de protección según lugar y actividad ante caso posible o confirmado de COVID-19 [Internet]. Junta de Castilla y León. [Consultado el 27 de mayo de 2020]. Disponible en: https://www. saludcastillayleon. es/es/covid-19/informacion-profesionales/prevencionriesgos-laborales.ficheros/1570999-Recomendaciones\%20 EPIs\%2Oseg\%C3\%BAn\%2Olugar\%20y\%2Oactividad.pdf

40. Shanthanna H, Strand NH, Provenzano DA, Lobo CA, Eldabe $S$, Bhatia $A$, et al. Caring for patients with pain during the COVID-19 pandemic: consensus recommendations from an international expert panel. Anaesthesia. 2020. DOI: 10.1111/anae.15076.

41. Shanthanna H, Cohen SP, Strand N, Lobo S, Eldabe S, Bhatia $A$, et al. Recommendation of chronic pain practice during the COVID-19 pandemic [Internet]. American Society of Regional Anesthesia and Pain Medicina. 27 de marzo de 2020 [Consultado el 27 de mayo de 2020]. Disponible en: https:// www. asra.com/page/2903/recommendations-on-chronicpain-practice-during-the-covid-19-pandemic

42. Schieber A, Ayres, J. Thermoregulation as a disease tolerance defense strategy. Pathog Dis. 2016;74(9):ftw106. DOI: 10.1093/femspd/ftw106. 
43. Evans SS, Repasky EA, Fisher DT. Fever and the thermal regulation of immunity: the immune system feels the heat. Nat Rev Immunol. 2015;15(6):335-49. D0I: 10.1038/ nri3843.

44. FMP response to concern related to the safety of steroids injected as part of pain procedures during the current COVID-19 virus pandemic. Faculty of Pain Medicine of the Royal College of Anaesthetists. 17 de marzo de 2020 [Consultadoel 27 de mayo de 2020]. Disponible en: https://fpm. ac.uk/sites/fpm/files/documents/2020-03/FPM-COVID19-Steroid-Statement-2020-v2.pdf

45. Fascia D, Dalili D, Rennie W, Rowbothan E, Carne A, Robinson R. The safety of corticosteroid injections during the COVID-19 global pandemic. British Society of Skeletal Radiologists. 19 de marzo de 2020 [consultado el 27 de mayo de 2020]. Disponible en: https://www.bssr.org.uk/static/ uploads/forum/Musculoskeletal_Radiology_during_the_ COVID-19 Global Pandemic.pdf

46. Popescu A, Patel J, Smith CC; on behalf of the Spine Intervention Society's Patient Safety Committee. Spinal Injections in Immunosuppressed Patients and the Risks Associated with Procedural Care: To Inject or Not to Inject? Spine Intervention Society. [Consultado el 27 de mayo de 2020]. Disponible en: https://cdn.ymaws.com/www. spineintervention.org/ resource/resmgr/factfinder/FactFinder 201901 Immunosup.pdf

47. Miller DC, Patel J, Gill J, Mattie R, Saffarian M, Schneider $\mathrm{BJ}$, et al. Corticosteroid Injections and COVID-19 Infection Risk. Spine Intervention Society. [Consultado el 27 de mayo de 2020]. Disponible en: https://cdn.ymaws.com/www. spineintervention.org/resource/resmgr/factfinder/2020/ sis factfinder 2005 covid19.pdf

48. Anti-inflammatoires non stéroïdiens (AINS) et complications infectieuses graves [Internet]. Agence Nationalede sécurité du médicament et des produits de santé. Actualizado el 20 de mayo de 2020. [Consultado el 27 de mayo de 2020]. Disponible en: https://www.ansm.sante.fr/S-informer/ Points-d-information-Points-d-information/Anti-inflammatoires-non-steroidiens-AINS-et-complications-infectieuses-graves-Point-d-Information-actualise-le-20-05-2020

49. EMA gives advice on the use of non-steroidal anti-inflammatories for COVID-19 [Internet]. European Medicines Agency Science Medicines Health. 18 de marzo de 2020 [Consultado el 27 de mayo de 2020]. Disponible en: https://www. ema.europa.eu/en/news/ema-gives-advice-use-non-steroidal-anti-inflammatories-covid-19

50. Diasso PDK, Birke H, Nielsen SD, Main KM, Højsted J, Sjøgren $P$, et al. The effects of long-term opioid treatment on the immune system in chronic non-cancer pain patients: $A$ systematic review. Eur J Pain. 2020;24(3):481-96. DOI: 10.1002/ejp. 1506.

51. Documento de preguntas y respuestas en torno al uso terapéutico no sustitutivo de plasma autólogo y sus fracciones, componentes o derivados [Internet]. Agencias Española de Medicamentos y Productos Sanitarios. 17 de enero de 2018 [consultado el 27 de mayo de 2020]. Disponible en: https://www.aemps.gob.es/medicamentosUsoHumano/ medSituacionesEspeciales/faqs-terapeutico-plasma-autologo.htm

52. Clinical trial [Internet]. U. S. National Library of Medicine. 2020 [Consultado el 27 de mayo de 2020]. Disponible en: https://clinicaltrials.gov/

53. Hernández A, Papadakos PJ, Torres A, González DA, Vives $M$, Ferrando $C$, et al. Dos terapias conocidas podrían ser efectivas como adyuvantes en el paciente crítico infectado por COVID-19. Rev Esp Anestesiol Reanim. 2020;67(5):24552. DOI: 10.1016/j.redar.2020.03.004.

54. Uso Potencial del Ozono en SARS-CoV-2 / COVID-19 ISCO3/ QAU/00/04 [Internet]. International Scientific Committee of Ozone Therapy. 13 de marzo de 2020 [consultado el 27 de mayo de 2020]. Disponible: https://aepromo.org/ coronavirus/pdfs doc ISCO3/Covid19 es.pdf

55. Oshima M, Deitiker PR, Jankovic J, Duane DD, Aoki $\mathrm{KR}$, Atassi MZ, et al. Human T-cell responses to botulinum neurotoxin. Responses in vitro of lymphocytes from patients with cervical dystonia and/or other movement disorders treated with BoNT/A or BoNT/B. J Neuroimmunol. 2011;240241:121-8. DOl: 10.1016/j.jneuroim.2011.10.005.

56. Kandasamy M. Perspectives for the use of therapeutic Botulinum toxin as a multifaceted candidate drug to attenuate COVID-19. Med Drug Discov. 2020;100042. DOI: 10.1016/j.medidd.2020.100042.

57. Save lives: clean your hands [Internet]. World Health Organization. 5 de mayo de 2020 [consultado el 27 de mayo de 2020]. Disponible en: https://www.who.int/infectionprevention/campaigns/clean-hands/5may2019/en/

58. Folgueira MD, Munoz-Ruiperez C, Alonso-Lopez MA, Delgado R. SARS-CoV-2 infection in Health Care Workers in a large public hospital in Madrid, Spain, during March 2020. Medrxiv 2020. DOl: 10.1101/2020.04.07.20055723.

59. Estudio Nacional de sero-Epidemiología de la Infección por SARS-CoV-2 en España (ENE-Covid) [Internet]. Ministerio de Sanidad. 13 de mayo de 2020 [consultado el 27 de mayo de 2020]. Disponible en: https://www.mscbs.gob.es/ciudadanos/ene-covid/home.htm

60. Coronavirus disease (COVID-19) advice for the public: When and how to use masks. World Health Organization. 2020 [consultado el 27 de mayo de 2020]. Disponible en: who. int/emergencies/diseases/novel-coronavirus-2019/advicefor-public/when-and-how-to-use-masks

61. Paniagua R. Siete tipos de mascarillas para combatir el coronavirus. EIPeriodico. Actualizada el 17 de abril de 2020 [consultado el 27 de mayo de 2020]. Disponible en: https://www. elperiodico.com/es/sociedad/20200407/ coronavirus-vueltas-con-las-mascarillas-7921125

62. Universidad de Navarra. Colocación, retirada y reutilización de la mascarilla [Video File]. 16 de abril de 2020. [Consultado el 27 de mayo de 2020] [2:13]. Disponible en: https://www. youtube.com/watch?v=M7-KyQHfPMO\&feature=youtu.be

63. Guidance for wearing and removing personal protective equipment in healthcare settings for the care of patients with suspected or confirmed COVID-19 [Internet]. European Centre for Disease Prevention and Contro. Febrero de 2020 [consultado el 27 de mayo de 2020]. Disponible en: https://www.ecdc.europa.eu/sites/default/files/documents/COVID-19-guidance-wearing-and-removing-personalprotective-equipment-healthcare-settings-updated.pdf

64. Sacyl. Recomendaciones para limpieza y desinfección de pantallas faciales [Internet]. Junta de Castilla y León. 2020 [consultado el 27 de mayo de 2020]. Disponible en: https://www. saludcastillayleon.es/es/covid-19/ informacion-profesionales/recomendaciones-profesionales. ficheros/1571032-Infograf\%C3\%ADa\%2ORecomendaciones\%20para\%2Olimpieza\%20y\%2Odesinfeci\%С3\%B3n\%20 de\%2Opantallas\%2Ofaciales.pdf

65. Ministerio de Sanidad. Productos virucidas autorizados en España [Internet]. 22 de mayo de 2020 [Consultado el 27 de mayo de 2020]. Disponible en: https://www.mscbs.gob. es/profesionales/saludPublica/ccayes/alertasActual/nCovChina/documentos/Listado_virucidas.pdf 